have expressed an opinion in favour of the existence of two planets at nearly the same mean distance. With respect to a period of twenty-eight days, we remark that reckoning from 1876 , April 4, it will agree with the observations of Lescarbault and Lummis, but not with that of Decuppis; while it also agrees with the observation of Stark, I8I9, October 9, a very definite one, which is not brought in with a period of forty-two days. The shorter period will be found to correspond with a mean distance of $0^{\prime} \mathrm{I} 8$.]

\section{SCIENCE IN SCHOOLS}

$7 \mathrm{HE}$ accompanying letter, signed by several men of Science and Head-masters, has been sent to the General Committee of the British Association :-

DEAR SIR,-It is hoped that a Committee may be formed at this year's meeting of the British Association for the promotion of Science Teaching in Schools. Its proposed functions would be--

I. To communicate with head-masters and governing bodies as to carrying out the recommendations contained in Report VI. of the Science Commission, and to offer advice, if required, on all necessary details of selection, arrangement, and outlay.

2. 'To press upon the Universities such steps in connection with the pending Bill in Parliament as may beneficially influence school teaching of science.

3. To watch the action of Government in any proposal made by them either in pursuance of Lord Salisbury's Bill or in giving effect to the Duke of Devonshire's Commission, and to hold a brief for science-teaching at schools in reference to all such legislation.

We desire to bespeak your attention to and interest in this proposal, which appears to us in all respects a timely one.

\section{THE BRITISH ASSOCIATION}

\section{GlasGow, Tuesday}

THE Association finds a fitting home in Glasgow, which has few rivals either in earlier or later scientific reputation. The force of long-continued scientific traditions, added to the present encouragement given to science, and I must also say, to the nearness of the finest holiday localities, makes this one of the most brilliant of recent meetings. Not only is the total number of members and associates attending very high, over 2,700 , but the true chiefs of science are present in great strength. It cannot be said that the Association itself is this year at all below its high aims. The majority of papers are really scientific, and do not emasculate the truth in the effort to popularise it. Discussions have been very interesting, judging from the perseverance with which they have been listened to. The reception given by the people of Glasgow is worthy of the city, although it is possible that in the details and refinements of arrangement, Bristol excelled. This was especially manifested in regard to some of the excursions. But it is evident that the very best efforts of the north have been put forth in every way, and the general result is undeniably successful. The charming situation of the University Buildings, in which all the sections but one hold their meetings, is a very great advantage.

From the Report of the Council it will be seen that grants in aid of scientific objects have been made during the year to the amount of $1,092 l$. The income of the year has reached $3,743 l$., and the cash balance, $764 l$., exceeded that of last year by $624 l$.

The President's Address did not excite general enthusiasm among the audience, partly because the great size of the building and the comparative weakness of the speaker's voice prevented many from hearing well, partly, also, because it was such as to impress most those who think most. The address manifested the combination in its author of qualities seldom marching together; deep regard for elder times and their achievements, wide knowledge of the position of science at the present day, perception of the true relationships, the real connexus of pure and applied science, a realisation, founded on careful study of the way in which the scientific cultus affects human nature, and the rise and fall of nations. It would be vain to seek for scientific arrogance and conceit in Dr. Andrews's deliverance, and if one may forecast, it may be expected to have as much influence on future thought and public action as almost any recent utterance from the presidential chair of the British Association, without any tendency to provoke the hostility of the unscientific.

Among the presidential addresses, that of Mr. Wallace to the Biological Section seems to have attracted much notice; and there is no doubt of its great value, for, scarcely occupying any ground covered by his recent great work on "The Geographical Distribution of Animals," he may be said to have laid the foundations of a new science out of "waste materials" already existing. Thus another group of scattered fragments is beginning to be sought by right processes, in order that a coherent edifice may be erected. Sir William Thomson returned again to the charge against the exorbitant demands of geologists for "time." If he is right, of course some geological theories must be altered; but perhaps Sir William will not have to wait long for an answer. It was singular that Prof. Young, in the Geolugical Section, should have chosen a subject agreeing so largely with Sir William Thomson's. His views, carried out into more geological detail, imply that we are to look for a general reconstruction of much that is held to be settled. in geological theory. He calls loudly for precision in geological phraseology, believing that there is nothing more urgently needed to secure progress in the science than some of that accuracy of conception and expression which distinguishes mathematical and physical science. Capt. Evans's address on Geography will perhaps disappoint some who think the questions of oceanic circulation are practically settled, but an open confession of difficulties and ignorance is better than any false security. Such confessions have been very general among the best men at this meeting-a favourable augury of coming victories for science.

On the whole the sections have done hard work, and comparatively little sacrifice of scientific rigour and form has been maade for the sake of making subjects popular. The Duke of Argyll's address on the Geology of the Highlands was a bonne bouche for the untechnical, and was much run after. The Duke has shared "lionship" with Commander Cameron and Sir C. Wyville Thomson; consequently the heart of Africa and the depths of the sea are among the favourite subjects here. Sir William Thomson has, of course, been at home on the great Tide question, denouncing the British Hydrographic Department for its supineness, by which very laborious and expensive efforts are left to private individuals. One of the most lively encounters has concerned the junction of the granites and Old Red Sandstone in Arran. It was suggested that Mr. Wünsch and Dr. Bryce should adjourn to the locality to fight it out, but without hammers. The chemists had a field-day on the disposal of the sewage of towns. Irrigationists and precipitationists continued their controversies, giving excuse to great towns still to postpone dealing with the subject. While the doctors, or rather chemists, differ, the sewage is emptied into the river.

Prof. Tait's discourse on Force was yery characteristic. One important advantage gained by the audience would probably be an impression of the necess: : of accuracy in the use of words.

Sir C. Wyville Thomson's address on tis Results of 
the Challenger Expedition was very successful, and highly appreciated. A good voice was added to a most agreeable and flowing delivery, and as little as possible of complicated ideas or reasoning was introduced.

Two conversaziones took place on Thursday evening, for what reason is not apparent. One was under the superintendence of the local committee, in the Royal Exchange. There was a little pretence at science, but the assembly was converted into a ball. Is it right that money raised by the local committee in the name of the British Association should be devoted to such a purpose? If a ball is wanted, let there be a separate subscription for that avowed purpose. The other assembly, under the auspices of the Philosophical Society (of which Sir William Thomson is president), took place in the Corporation Galleries and the rooms of the Society. Art and science were here fitly combined. Physical apparatus received considerable illustration. Sir William Thomson's demonstration on smoke rings and his new patent syphon recorder being especially interesting. Mr. James Thomson, F.G.S., attracted attention by his exhibition of a series of sections of fossil corals, beautifully shown by Birrell's new oxyhydrogen apparatus. The great special collection of carboniferous fossils in these galleries was exceedingly creditable to the geologists of the Glasgow district; Mr. James Thomson's very large collections, including his splendid Labyrinthodont remains (Pteroplax, \&c.), formed a considerable proportion of the whole.

The museums of Glasgow are numerous and scattered. To a conisiderable extent the same things are displayed over again in the Hunterian Museum at the University, the Kelvingrove Museum in the park of that name, the Andersonian at Anderson's University, the Museum of the Society of Naturalists in the Queen's Rooms, and the Museum in the Corporation Galleries. Very great labour has been expended in the formation of special collections at these places, but we can only notice a very few of these. In the University Museum the display of Mr. John Young's private collection of fossils was most interesting by reason of the great number and beauty of the preparations of minute forms, especially of Foraminifera, Sponges, Echinoderms and Polyzoa. Unfortunately the great roof of the Museum has no light in it whatever, an inconceivable detraction from its value. Other most noticeable collections were a splendid series of Labyrinthodonts and Fishes from Carluke Collieries, the exhibitor of which desired his name to be unknown, and Mr. David Robertson's collection of recent and Pleistocene invertebrates. The great special exhibition of mechanical inventions and industrial processes at the Kelvingrove Museum must, we regret to say, be dismissed with a single word of high commendation. Rare plants and animals were to be seen at the Queen's Rooms, including many unique specimens from Scottish habitats. Utricularia and Drosera are of course brought forward.

The assembly of foreigners on this occasion is very notable. Section A includes in its forces Prof. Cremona, of Rome; M. Janssen, of Leyden; Prof. Wuillner, of Aix-la-Chapelle; Prof. Eccher, of Florence; Prof. Fischer, Prof, von Quintus Icilius, of Hanover; Profs. Stoletow and Wladirmiosky. Section $B$ has the aid of Dr. Biedermann, of Berlin. Section C, Dr. A. Fritsch, of Prague : Prof, von Lasaulx, of Breslau? Prof. F. Roemer, of Breslau; Section D rejoices in the presence of Ferdinand Cohn and Grube, of Breslau; Ernst Haeckel, of Jena; Kronecker, of Leipsic; and Prof. Morren, of Liége; the Chevalier Negri reinforces Section $E$; and M. Bergeron, of Puris, Section G.

The excursion programme, as might be expected in this neighbourh uod, has been only too embarrassing. Saturday was . ry generally devoted to pleasure, although the mathem . icians and physicists cleared oft a long list of papers, and two other sections sat during part of the day. Those who could not devote the whole day fo excursions had abundant entertainment provided for them in Glasgow. Cameron's lecture to working men was naturally very successful, and Dr. Carpenter subsequently spoke at length on the humane treatment which should be accorded to savages. One of the most interesting trips was made by Mr. Duncan and a small party of zoologists to Loch Fyne and the coast of Bute for the purpose of dredging. Many successful hauls were made, bringing up abundance of Comatulas, Aphrodites, Ascidians, and Echini. Another dredging party went with Mr. A. B. Stewart to Wemyss Bay. An attempt at dredging in Loch Lomond only gave "a beggarly account of empty bags." A geological party went to Ballagan, Finnich Glen, \&c., under the guidance of Mr. Wilson, of Aucheveck. No very special scientific interest appears to be included in the excursions for Thursday next, when Paisley Abbey, Arran, Rothesay, and Loch Long, are to be visited.

So we are to meet in Dublin in 1878 . Leeds pleaded hard, claiming that there was a sort of understanding in their favour last year. But the idea of alternating the meetings between a university town and a great manufacturing town prevailed, in addition, no doubt, to the eminence of the Dublin academicians attending the meeting. Scarcely less interesting was the choice of a president for the Plymouth meeting. The nomination of Prof. Allen Thomson by Dr. Hooker was at once an honour to Glasgow and a demonstration of regard for those studies of anatomy and embryology which do not always secure public renown. The personal qualities of Dr. Allen Thomson make him all that could be desired for a president. Of course his nomination was unanimously accepted. The vice-presidents appointed were the Earl of Mount-Edgcumbe, the Earl of Devon, Lord Blachford, Mr.W. Spottiswoode, F.R.S., Mr. W. Froude, F.R.S., and Mr. C. Spence Bate, F.R.S.; local secretaries, Prof. W. G. Adams, Mr. W. Square, and Mr. Hamilton Whiteford. Mr. P. L. Sclater, F.R.S., was elected one of the general secretaries, in the place of Dr. Michael Foster, F.R.S., who has resigued. We meet again in Plymouth on August 1 5, 1877.

\section{SECTION A.}

MATHEMATICAL AND PHYSICAL

\section{Opening Address by Prof. Sir William Thomson,} F.R.S., D.C.L., \&C., PRESIDENT.

A CONVERsation which I had with Prof. Newcomb one evening last June, in Prof. Henry's drawing.room, in the Smithsonian Institution, Washington, has forced me to give all my spare thoughts ever since to Hopkins's problem of Precession and Nutation, assuming the earth a rigid spheroidal shell filled with liquid. Six weeks ago, when I landed in England after a most interesting trip to America and back, and became painfully conscious that I must have the honour to address you here to. day, I wished to write an address of which science in America should be the subject. I came home, indeed, vividly impressed with much that I had seen both in the Great Exhibition of Philadelphia and out of it, showing the truest scientific spirit and devotion, the originality, the inventiveness, the patient: persevering thoroughness of work, the appreciativeness, and the generous openmindedness and sympathy, from which the great things of science come.

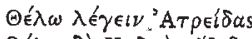

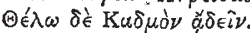

I wish I could speak to you of the veteran Henry, generous rival of Faraday in electromagnetic discovery; of Peirce the founder of high mathematics in America ; of Bache, and of the splendid heritage he has left to America and to the world in the United States Coast Survey ; of the great school of astronomers which followed, Gould, Newton, Newcomb, Watson, Young, Alvan Clarke, Rutherford, Draper, father and son : of Commander Belknap and his great exploration of the Pacific depths by pianoforte wire, with imperfect apparatus supplied from Glas. gow, out of which he forced a success in his own way; 
of Captain Sigsbee, who followed with like fervour and resolution, and made further improvements in the apparatus by which he has done marvels of easy, quick, and sure deepsea sounding in his little surveying ship Blake; and of the admirable official spirit which makes such men and such doings possible in the United States Naval Service. I would like to tell you too of my reason for confidently expecting that American hydrography will soon supply the data from tidal observations, long ago asked of our Government in vain by a Committee of the British Association, by which the amount of the earth's elastic yielding to the distorting influence of the sun and moon will be measured; and of my strong hope that the Compass Department of the American Navy will repay the debt to France, England, and Germany so appreciatively acknowledged in their reprint of the works of Poisson, Airy, Archibald Smith, Evans, and the Liverpool Compass Committee, by giving in return a fresh marine survey of terrestrial magnetism, to supply the navigator with data for correcting his compass without sights of sun or stars.

Can I go on to precession and nutation without a word of what $I$ saw in the Great Exhibition of Philadelphia? In the U.S. Government part of it, Prof. Hilgard showed me the measuring-rods of the U.S. Coast Survey, with their beautiful mechanical appliances for end measurement, by which the three great base lines of Maine, Long Island, and Georgia, were measured with about the same accuracy as the most accurate scientific measurers, whether of Europe or America, have attained in comparing two metre or yard measures.

In the United States telegraphic department I saw and heard Elisha Gray's splendidly worked-out electric telephone actually sounding four messages simultaneously on the Morse code, and clearly capable of doing yet four times as many with very moderate improvements of detail ; and I saw Edison's automatic telegraph delivering $\mathrm{r}, 015$ words in 57 seconds; this done by the long-neglected electro-chemical method of Bain, long ago condemned in England to the helot work of recording from a relay, and then turned adrift as needlessly delicate for that. In the Canadian department I heard "To be or not to be, . . . . there's the rub," through an electric telegraph wire; but, scorning monosyllables, the electric articulation rose to higher flights, and gave me passages taken at random from the New York newspapers:-"S.S. Cox has arrived" (I failed to make out the S.S. Cox) ; "The City of New York," "Senator Morton," "The Senate has resolved to print a thousand extra copies;" "The Americans in London have resolved to celebrate the coming 4th of July." All this my own ears heard, spoken to me with unmistakable distinctness by the thin circular disc armature of just such another little electro-magnet as this which I hold in my hand. The words were shouted with a clear and loud voice by my colleague-judge, Prof. Watson, at the far end of the telegraph wire, holding his mouth close to a stretched membrane, such as you see before you here, carrying a little piece of soft iron, which was thus made to perform in the neighbourhood of an electro-magnet in circuit with the line motions proportional to the sonorific motions of the air. This, the greatest by far of all the marvels of the electric telegraph, is due to a young countryman of our own, Mr. Graham Bell, of Edinburgh and Montreal, and Boston, now becoming a naturalised citizen of the United States. Who can but admire the hardihood of invention which devised such very slight means to realise the mathematical conception that, if electricity is to convey all the delicacies of quality which distinguish articulate speech, the strength of its current must vary continuously and as nearly as may be in simple proportion to the velocity of a particle of air engaged in constituting the sound?

The Patent Museum of Washington, an institution of which the nation is justly proud, and the beneficent working of the United States patent laws, deserve notice in the section of the British Association concerned with branches of science to which nine-tenths of all the useful patents of the world owe their foundations. I was much struck with the prevalence of patented inventions in the Exhibition : it seemed to me that every good thing deserving a patent was patented. I asked one inventor of a very good invention "Why don't you patent it in England?" He answered, "The conditions in England are too onerous." We certainly are far behind America's wisdom in this respect. If Europe does not amend its patent laws (England in the opposite direction to that proposed in the Bills before the last two sessions of Parliament) America will speedily become the nursery of useful inventions for the world.

I should tell you also of "Old Prob's" weather warnings, which cost the nation 250,000 dollars a year; money well spent say the western farmers, and not they alone : in this the whole people of the United States are agreed, and though Democrats or Republicans playing the "economical ticket" may for half a session stop the appropriations for even the United States Coast Survey, no one would for a moment think of proposing to starve "Old Prob;" and now that 80 per cent. of his probabilities have proved true, and General Myers has for a month back ceased to call his daily forecasts "probabilities" and has begun to call them indications, what will the western farmers call him this time next year?

And the United States Naval Observatory, full of the very highest science, under the command of Admiral Davis! If, to get on to precession and nutation, I had resolved to omit telling you that I had there, in an instrument for measuring photographs of the transit of Venus-shown me by Prof. Harkness, a young Scotsman attracted into the United States Naval Service-seen for the first time in an astronomical observatory a geometrical slide, the verdict on the disaster on board the Thunderer, published while I am writing this address, forbids me to keep any such resolution, and compels me to put the question, Is there in the British Navy, or in a British steamer, or in a British land boiler another safety-valve so constructed that by any possibility, at any temperature, or under any stress it can jam? and to say that if there is it must be instantly corrected or removed.

I ought to speak to you, too, of the already venerable Harvard University, the Cambridge of America, and of the Technological Institute of Boston, created by William Rogers, brother of my late colleague in this university (Glasgow), Henry Rogers, and of the Johns Hopkins University of Baltimore, which with its youthful vigour has torn Sylvester from us, has utilised the genius and working power of Roland for experimental research, and three days after my arrival in America, sent for the young Porter Poinier to make him a Fellow. But he was on his death. bed in New York " begging his physicians to keep him alive just to finish his book, and then he would be willing to go." Of his book, "Thermodynamics," we may hope to see at least a part, for much of the manuscript, and good and able friends to edit it, are leit; but the appointment to a Fellowship in the Johns Hopkins University came a day too late to gratify his noble ambition.

But the stimulus of intercourse with American scientific men left no place in my mind for framing, or attempting to frame a report on American science. Disturbed by Newcomb's sus. picions of the eartin's irregularities as a Time-keeper, I could think of nothing but precession and nutation, and tides and monsoons, and settlements of the equatorial regions, and melting of polar ice. Week aiter week passed before I could put down two words which I could read to you here to-day : and so I have nothing to offer you for my Address but-

Review of Evidence regarding Physical Condition of the Earth; its Internal Temperature? the Fluidity or Solidity of its Interior Substance; the Rigidity, Elasticity, Plasticity, of its External Figure; and the Permanence or Variability of its Period and Axis of Rotation.

The evidence of a high internal temperature is too well known to need any quotation of particulars at present. Suffice it to say that below the uppermost ten metres stratum of rock or soil sensibly affected by diurnal and annual variations of temperature, there is generally found a gradual increase of temperature downwards, approximating roughly, in ordinary localities, to an average rate of $\mathrm{I}^{\circ} \mathrm{C}$. per thirty metres of descent, but much greater in the neighbourhood of active volcanoes, and certain other special localities of comparatively small area, where hot springs and, perhaps, also, sulphurous vapours prove an intimate relationship to volcanic quality. It is worthy of remark in passing, that, so far as we know at present, there are no localities of exceptionally small rate of augmentation of underground temperature, and none where temperature diminishes at any time through any considerable depth downwards below the stratum sensibly influenced by summer heat and winter cold. Any considerable area of the earth of, say, not less than a kilometre in any horizontal diameter, which for several thousand years had been covered by snow or ice, and from which the ice had melted away and left an average surface temperature of $13^{\circ}$, would during nine hundred years, show a decreasing temperature for some depth down from the surface: and thirtysix hundred years after the clearing away of the ice would still show residual effect of the ancient cold, in a half rate of augmen- 
tation of temperature downwards in the upper strata, gradually increasing to the whole normal rate which would be sensibly reached at a depth of 600 metres.

By a simple effort of geological calculus it has been estimated that $x^{\circ}$ per 30 metres gives $1000^{\circ}$ per 30,000 metres, and $3333^{\circ}$ per too kilometres. This arithmetical result is irrefragable, but what of the physical conclusion drawn from it with marvellous frequency and pertinacity that at depths of from 30 to 100 kilometres the temperatures are so high as to melt all substances composing the earth's upper crust? It has been remarked, indeed, that if observation showed any diminution or augmentation of the rate of increase of underground temperature in great depths, it would not be right to reckon on the uniform rate of $x^{\circ}$ per 30 metres, or thereabouts, down to 30 or 60 or 100 kilometres. "But observation has shown nothing of the kind, and therefore surely it is most consonant with inductive philosophy to admit no great deviation in any part of the earth's solid crust from the rate of increase proved by observation as far as the greatest depths to which we rave reached !" Now I have to remark upon this argument that the greatest depth to which we have reached in observations of underground temperature is scarcely one kilometre; and that, if a, 10 per cent. diminution of the rate of augmentation of underground temperature downwards were found at a depth of one kilometre, this wovid demonstrate ${ }^{x}$ that within the last 100,000 years the upper surface of the earth must have been at a higher temperature than that now found at the depth of one kilometre. Such a result is no doubt to be fonnd by observation in places which have been overflown by lava in the memory of man, or a few thousand years farther back : but if, without going deeper than a kilometre, a Io per cent. diminution of the rate of increase of temperature dowriwards were found for the whole earth, it would limit the whole of geological history to within 100,000 years, or, at all events, would interpose an absolute barrier against the contimuous descent of life on the earth from earlier periods than 100,000 years ago. Therefore, although search in particular localities for a diminution of the rate of angmentation of underground temperature in depths of less than a kilometre may be of interise interest, as helping us to $\mathrm{fx}_{\mathrm{x}}$ the dates of extinct volcanic actions which have taken place within 100,000 years or so, we lnnow enough from thoroughly sure geological evidence not to expect to find it, excent in particular localities, and to feel quite sure that we shall not find it under any considerable portion of the earih's surface. If we admit as possible any such discontinuity within 900,000 years, we might be prepared to find a sensible diminution of the rate at three kilometres depih: but not at anything less than 30 kilometres if geologists validly claim as much as $90,000,000$ of years for the length of the time with which their science is concerned. Now this implies a temperature of $1000^{\circ}$ C. at the depth of 30 kilometres, allows something less than $2000^{\circ}$ for the temperature at 60 kilometres, and does not require much more than $4,000^{\circ} \mathrm{C}$. at any depth, however great; but does require at the great depths a temperature of at all events not less than about $4000^{\circ} \mathrm{C}$. It would not take much "hurrying up" of the actions with which they are concerned, to satisfy geclogists with the more moderate estimate of $50,000,000$ of years. This would imply at least abont $3000^{\circ}$ C. for the limiting temperature at great depths. If the actual substance of the earth, whatever it may be, rocky or metallic, at depths of from 60 to roo kilometres, under the pressure actually there experienced by it can be solid at temperatures of from $3000^{\circ}$ to $4000^{\circ}$, then we may hold the former estimate $(90,000,000)$ to be as probable as the latter $(50,000,000)$ so far as evidence from underground temperature can guide us. If $4000^{\circ}$ would melt the earth's substance at a depth of 100 kilonetres, we must reject the former estimate, though we might still admit the latter; if $3000^{\circ}$ would melt the substance at a depth of 60 kilometres, we should be compelled to conclude that $50,000,000$ of years is an over-estimate. Whatever may be its age, we may be quite sure the earth is solid in its interior: not, I admit, thronghont its whole volume, for there certainly are spaces in volcanic regions occupied by liquid lava; but whato ever portion of the whole mass is liquid, whether the waters of the ocean or melted matter in the interior, these portions are small in comparison with the whole, and we must utterly reject any geological hypothesis which, whether for explaining under.

I For proof of this and following statements regarding Underground Heat I refer to "Secular Cooling of the Earth" Transactions of the Royal Society of Edinburgh, x862, and Thomson and Tait's "Natural Philosophy, Appendix D. ground heat or ancient upheavals and subsidences of the solid crust, or earthquakes, or existing volcanoes, assumes the solid earth to be a shell of 30 , or 100 , or 500 , or 1,000 kilometres tảickness, resting on an interior liquid mass.

This conclusion was first arrived at by Hopkins, who may therefore properly be called the discoverer of the earth's solidity. He was led to it by a consideration of the phenomena of precession and nutation, and gave it as shown to be highly probable, if not absolutely demonstrated, by his confessedly imperfect and tentative investigation. But a rigorous application of the perfect hydrodynamical equations leads still more decidedly to the same conclusion.

I am able to say this to you now in consequence of the con. versation with Prolessor Newcomb to which I have already alluded. Admitting fally my evidence for the rigidity of the earth from the tides, he doubted the aryument from precession and nutation. Trying to recollect what I had written on it fourteen years ago in a paper on the Rigidity of the Earth, published in the Transactions of the Royal Society, my con. science smote me, and I could only siammer out that I had convinced myself that so and so, and so and so, at which $I$ had arrived by a non-mathematical short cut, were true. He hinted that viscosity might suffice to render precession and nutation the same as if the earth were rigid, and so vitiate the argument for rigidity. This I could not for a moment admit any more than when it wras first put forward by Delaunay. But doult entered mind regarding the so and so, and so and so; and I had not completed the night journey to Philadelphia which hurried me away from our unfinished discussion before I had convinced myself that they were grievously wrong. So now I must request as a favour that each one of you on going home will instantly turn up his or her copies of the Transactions of the Royal Society for I 862 , and of Thomson and Tait's "Natural Philosophy," vol. i., and draw the pen through \$s 23-3I of my paper on the "Rigioity of the Earth" in the former, ard tirough everything in $\$ \$ 347.849$ of the latier, which refers to the effect on precession and nutation of an clastic yielding of the earth's surface.

When those passages were written I knew Iittle or nothing of vortex motion; and until my attention was recalled to thern by Prof. Newcomb, I had never once thought of their subject in the light thrown upon it by the theory of the quasi-rigidity induced in a liquid by vortex motion which has of late occupied me so much. With this fresh light a little consideration sufficed. to show me that (although the old obvious conciusion is of course true, that if the inner boundary of the imagined rigid shell of the earth were rigorously spherical, the interior liquid could experience no precessional or nutational infuence from the pressure on its bounding surface, and therefore if homogeneons could have no precession or nutation at all, or if heterogeneous only as much precession and nutation as would be produced by attraction from without in virtue of non-sphericity of its surfaces of equal density, and therefore the shell would have enormously more rapid precession and nutation than it actually has-forty times as much, for instance, if the thickness of the shell is sixty kilometres) a very slight deviation of the inner surface of the sheil from perfect sphericity would suffice, in virtue of the quasirigidity due to vortex moiron, to hold back the shell from taking sensibly more precession than it would give to the liquid, and to cause the liquid (homogeneous or heterogeneous) and the shell to have sensibly the sarne precessional motion as if the whole constituted one rigid body. But it is only because of the very long period (26,000 years) of precession, in comparison with the period of rotation (one day), that a very slight deviation fiom sphericity would suffice to cause the whole to move as if it were a rigid body. A little further consideration showed me-

(I) That an ellipticity of inner surface equal to $\frac{1}{26000 \times 365}$ would be too smail, but that an ellipticity of one or two hundred times this amount would not be too small, to compel approximate equality of precession throughout liquid and shell.

(2) That with an ellipticity of interior surface equal to $\frac{1}{3} \sigma$, if the precessional motive were 26,000 times as great as it is, the motion of the liquid would be very different from that of a rigid mass rigidly connected with the shell :

(3) That with the actual forces and the supposed interior ellipticity of $\frac{1}{3 \frac{1}{b 0}}$ the lunar nineteen-yearly nutation might be affected to about five per cent. of its amount by interior liquidity.

(4) Lastly, that the lunar semi-annual nutation must be largely, 
and the lunar fortnightly nutation enormously, affected by interior liquidity.

But although so much could be foreseen readily enough, I found it impossible to discover, without thorough mathematical investigation, what might be the characters and amounts of the deviations from a rigid body's motion which the several cases of precession and nutation contemplated would present. The investigation, limited to the case of a homogeneous liquid enclosed in an ellipsoidal shell, has brought out results which I confess have greatly surprised me. When the interior ellipticity of the sheil is just too small, or the periodic speed of the disturbance just too great to allow the motion of the whole to be sensibly that of a rigid body, the deviation first sensible renders the precessional or nutational motion of the shell smaller than if the whole were rigid, instead of greater, as I expected. The amount of this difference bears the same proportion to the actual precession or nutation as the fraction measuring the periodic speed of the disturbance (in terms of the period of rotation as unity) bears to the fraction measur. ing the interior ellipticity of the shell ; and it is remarkable that this result is independent of the thickness of the shell, assumed however to be small in proportion to the earth's radius. Thus in the case of precession the effect of interior liquidity would be to diminish the periodic speed of the precession in the proportion stated; in other words, it would add to the precessional period a number of days equal to the multiple of the rotational period equal to the number whose reciprocal measures the ellipticity. Thus in the actual case of the earth if we still talse $-\frac{1}{0} \pi$ as the ellipticity of the inner boundary of the supposed rigid shell, the effect would be to augment by 300 days the precessional period of 2,600 years, or to diminish by about $\frac{1}{60}$ " the annual precession of about $5 \mathrm{I}^{\prime \prime}$-an effect which I need not say would be wholly insensible. But on the lunar nutation of 18.6 years period the effect of interior liquidity would be quite sensible; i 8.6 years being 23 times 300 days, the effect would be to diminish the axes of the ellipse which the earth's pole describes in this period each by $\frac{1}{13}$ of its own amount. The semi-axes of this ellipse calculated on the theory of perfect rigidity from the very accurately known amount of precession and the fairly accurate knowledge which we have of the ratio of the lunar to the solar part of the precessional motive are $9^{\prime \prime} \cdot 22$ and $6^{\prime \prime} \cdot 86$, with an uncertainty not amounting to one-half per cent. on account of want of perfect accuracy in the latter part of data. If the true values were less each by $\frac{1}{2}$ s of its own amount, the discrepance might have escaped detection, or might not have escaped detection; but certainly could be found if looked for. So far nothing can be considered as absolutely proved with reference to the interior solidity of the earth from precession and nutation; but now think of the solar semi-annual and the lunar fortnightly nutations. The period of each of these is less than 300 days. Now the hydro. dynamical theory shows that irrespectively of the thickness of the shell, the nutation of the crust would be zero if the period of the nutational disturbance were 300 times the period of rotation (the ellipticity being $\frac{1}{30}$ ): if the nutational period were anything between this and a certain smaller critical value depending on the thickness of the crust, the nutation would be negative; if the period were equal to this second critical value, the nutation would be infinite: and if the period were still less, the nutation would be again positive. Farther the 183 days period of the solar nutation falls so little short of the critical 300 days, that the amount of the nutation is not sersibly influenced by the thickness of the crust-is negative and equal in absolute value to $\frac{61}{39}$ (being the reciprocal of $\frac{3}{1} \frac{00}{83}-$ I) times what the amount would be were the earth solid throughout. Now this amount as calculated in the Nautical Almanac makes $\mathrm{O}^{\prime \prime} \cdot 55$, and $\mathrm{O}^{\prime \prime} \cdot 5 \mathrm{I}$ the semi-axes of the ellipse traced by the earth's axis round its mean position; and if the true nutation placed the earth's axis on the opposite side of an ellipse having ".86 and ".8I for its semi-axes, the discrepance could not possibly have escaped detection. But lastly, think of the lunar fortnightly nutation. Its period is $\frac{1}{20}$ of 300 days, and its amount, calculated in the Nautical Almanac on the theory of complete solidity, is such that the greater semi-axis of the approximately circular ellipse described by the pole is $0^{\prime \prime} \cdot 0325$. Were the crust infinitely thin this nutation would be negative, but its amount nineteen times that corresponding to solidity. This would make the greater semi-axis of the approximately circular ellipse described by the pole amount to $19 \times \mathrm{O}^{\prime \prime} \cdot 0885$, which is $I^{\prime \prime} \cdot 7$. It would be negative and of some amount between $I^{\prime \prime} \cdot 7$ and infinity, if the thickness of the crust were anything from zero to 120 kilometres. This conclusion is absolutely decisive against the geological hypothesis of a thin rigid shell full of liquid.

But interesting in a dynamical point of view as Hopkins's problein is, it cannot afford a decisive argument against the earth's interior liquidity. It assames the crust to be perfectly stiff and unyielding in its figure. This of course it cannot be, because no material is infinitely rigid; but, composed of rock and possibly of continuous metal in the great depths, may the crust not as a whole be stiff enough to practically fulfil the condition of unyieldingness? No; decidedly it could not: on the contrary, were it of continuous steel and 500 kilometres thick, it would yield very nearly as much as if it were india-rubber, to the deforming influences of centrifugal force and of the sun's and moon's attractions. Now, although the full problem of precession and nutation, and what is now necessarily included in it-tides, in a continuous revolving liquid spheroid, whether homogeneous or heterogeneous, has not yet been coherently worked out, I think I see far enough towards a complete solution to say that precession and nutations will be practically the same in it as in a solid globe, and that the tides will be practically the same as those of the equilibrium theory. From this it follows that precession and nutations of the solid crust, with the practically perfect flexibility which it would have even though it were Ioo kilometres thick and as stiff as steel, would be sensibly the same as if the whole earth from sur. face to centre were solid and perfectly stiff. Hence precession and nutations yield nothing to be said against such hypotheses as that of Darwin, ${ }^{\mathrm{I}}$ that the earth as a whole takes approximately the figure due to gravity and centrifugal force, because of the fluidity of the interior and the flexibility of the crust. But alas for this "attractive sensational idea that a molten interior to the globe un. derlies a thin superficial crust; its surface agitated by tidal waves and flowing freely towards any issue that may here and there be opened for its outward escape," as Poulett Scrope called it ! the solid crust would yield so freely to the deforming influence of sun and moon that it would simply carry the waters of the ocean up and down with it, and there would be no sensible tidal rise and fall of water relatively to land.

The state of the case is shorily this:-The hypothesis of a perfectly rigid crust containing liquid violates physics by assuming pretenaturally rigid matter and violates dynamical astronomy in the solar semi-annual and lunar fortnightly nutations; but tidal theory has nothing to say against it. On the other hand the tides decide against any crust flexible enough to perform the nutations correctly with a liquid interior, or as flexible as the crust must be unless of preternatirally rigid matter.

But now thrice to slay the slain; suppose the earth this moment to be a thin crust of rock or metal resting on liquid matter. Its equilibrium would be unstable! And what of the upheavals and subsidences? They would be strikingly analogous to those of a ship which has been rammed : one portion of crust up and another down, and then all down. I may say with almost perfect certainty, that, whatever may be the relative densities of rock, solid and meited, at or about the temperature of liquefaction, it is, I think, quite certain that cold solid rock is denser tilian hot melted rock: and no possible degree of rigidity in the crust could prevent it from breaking in pieces and sinking wholly below the liquid lava. Something like this may have gone on and probably did go on for thousands of years after solidification commenced; surface portions of the meited mate. rial Josing heat, freezing, sinking immediately, or growing to thicknesses of a few metres when the surface would be cool and the whole solid dense enough to sink. "This process must go on until the sunk portions of crust build up from the bottom a sufficiently close-ribbed skeleton or frame, to allow fresh incrus. tations to remain bridging across the now small areas of lava, pools, or lakes.

"In the honey-combed solid and liquid mass thus formed, there must be a continual tendency for the liquid, in consequence of its less specific gravity, to work its way up; whether by masses of solid falling from the roofs of vesicles or tumnels, and causing earthquake shocks, or by the roof breaking quite through when very thin, so as to cause two such hollows to unite or the liquid of any of them to flow out freely over the outer surface of the earth; or by gradual subsidence of the solid owing to the thermodynamic melting, which portions of it under intense stress must experience according to my brother's theory. The results which must follow from this tendency seem sufficiently great and

I "Observations on the Parallel Roads of Glen Roy and other Parts of Lochaber in Scotland, with an Attempt to prove that they are of Marine Origin."-Transactions of the Royal Society for Feb. 1839 , p. 8I. 
various to account for all that we learn from geological evidence of earthquakes, of upheavals and subsidences of solid, and of eruptions of melted rock." 1

Leaving altogether now the hypothesis of a hollow shell filled with liquid, we must still face the question, how much does the earth, solid throughout, except small cavities or vesicles filled with liquid, yield to the deforming (or tide-generating) influences of sun and moon? This question can only be answered by observation. A single infinitely accurate spirit-level or plummet far enough away from the sea to be not sensibly affected by the attraction of the rising and falling water, would enable us to find the answer. Observe by level or plummet the changes of direction of apparent gravity relatively to an object rigidly connected with the earth, and compare these changes with what they would be were the earth perfectly rigid, according to the known masses and distances of sun and moon. The discrepance, if any is found, would show distortion of the earth, and would afford data for determining the dimensions of the elliptic spheroid into which a non-rotating globular mass of the same dimensions and elasticity as the earth would be distorted by centrifugal force if set in rotation, or by tide-generating influence of sun or moon. The effect on the plumb-line of the lunar tide-generating influence is to deflect it towards or from the point of the horizon nearest to the moon, according as the moon is above or below the horizon. The effect is zero when the moon is on the horizon or overhead, and is greatest in either direction when the moon is $45^{\circ}$ above or below the horizon. When this greatest value is reached, the plummet is drawn from its mean position through a space equal to $13 \frac{1}{000}$ of the length of the thread. No ordinary plummet or spirit-level could give any perceptible indication whatever of this effect; and to measure its amount it would be necessary to be able to observe angles as small as

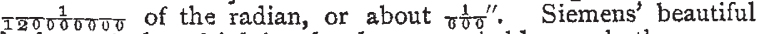
hydrostatical multiplying level may probably supply the means for doing this. Otherwise at present no apparatus exists within small compass by which it could be done. A submerged waterpipe of considerable length, say twelve kilometres, with its two ends turned up and open might answer. Suppose, for example, the tube to lie North and South, and its two ends to open into two small cisterns, one of them, the southern, for example, of half a decimetre diameter (to escape disturbance from capillary attraction); and the other of two or three decimetres diameter (so as to throw nearly the whole rise and fall into the smaller cistern). For simplicity suppose the time of observation to be when the moon's declination is zero. The water in the smaller or southern cistern will rise from its lowest position to its highest position while the moon is rising to maximum altitude, and fall again after the moon crosses the meridian till she sets; and it will rise and fall again through the same range from moonset to moonrise. If the earth were perfectly rigid, and if the locality is in latitude $45^{\circ}$, the rise and fall would be half a millimetre on each side of the mean level; or a little short of half a millimetre if the place is within $10^{\circ}$ north or south of latitude $45^{\circ}$. If the air were so absolutely quiescent during the observations as to give no varying differential pressure on the two water surfaces to the amount of $\frac{1}{100}$ millimetre of water, or $\frac{1}{1400}$ of mercury, the observation would be satisfactorily practicable, as it would not be difficult by aid of a microscope to observe the rise and fall of the water in the smaller cistern to $\frac{1}{10}$ of a millimetre; but no such quiescence of the atmosphere could be expected at any time, and it is probable that the variations of the water-level due to difference of the barometric pressure at the two ends would in all ordinary weather quite overpower the small effect of the lunar tidegenerating motive. If, however, the two cisterns instead of being open to the atmosphere were connected air-tightly by a return pipe with no water in it, it is probable that the observation might be successfully made : but Siemens' level or some other apparatus on similarly small scale would probably be preferable to any elaborate method of obtaining the result by aid of very long pipes laid in the ground; and I have only called your attention to such an ideal method as leading up to the natural phenomenon of tides.

Tides in an open canal or lake of twelve kilometres length would be of just the amount which we have estimated for the cisterns connected by submerged pipe ; but would be enormously more disturbed by wind and variations of atmospheric pressure. A canal or lake of 240 kilometres length, in a proper direction and in a suitable locality, would give but ten millimetres rise

x "Secular Ccoling of the Earth." Transactions of the Royal Society of Edinhurgh, 1862 (W. Thomson), and Thomson and Tait's "Natural Philosophy," \$\$(ee), (ff). and fall at each end, an effect which might probably be analysed out of the much greater disturbance produced by wind and differences of barometric pressure; but no open liquid level short of the ingens equor, the ocean, will probably be found so well adapted as it for measuring the absolute value of the disturbance produced on terrestrial gravity by the lunar and solar tide genernting motive. But observations of the diurnal and semi-diurnal tides in the ocean, do not (as they would on smaller and quicker levels) suffice for this purpose, because their amounts differ enormously from the equilibrium values on account of the smallness of their periods in comparison with the periods of any of the grave enough modes of free vibration of the ocean as a whole. On the other hand, the lunar fortnightly declinational and the lunar monthly elliptic and the solar semi-annual and annual elliptic tides have their periods so long that their amounts must certainly be very approximately equal to the equilibrium values.

But there are large annual and semi-annual changes of sea level, probably both differential on account of wind and differences of barometric pressure and differences of temperature of the water, and absolute depending on rain-fall and the melting away of snow and return evaporation, which altogether swamp the small semi-annual and annual tides due to the sun's attraction. Happily, however, for our object there is no meteorological or other disturbing cause which produces periodic changes of sea.level in either the fortnightly declinational or the monthly elliptic period; and the lunar gravitational tides in these periods are therefore to be carefully investigated in order that we may obtain the answer to the interesting question, how much does the earth as an elastic spheroid yield to the tidegenerating influence of sun or moon? Hitherto in the British Association Committee's reductions of Tidal Observations we hare not succeeded in obtaining any trustworthy indications of either of these tides. The St. George's pier landing-stage pontoon, unhappily chosen for the Liverpool tide gauge cannot be trusted for such a delicate investigation; the available funds for calculation were expended before the long-period tides for Helbre Island could be attacked, and three years of Kurrachee gave our only approach to a result. Comparisons of this, with an indication of a result with calculations on West Hartlepool tides, conducted with the assistance of a grant from the Royal Suciety, seem to show possibly no sensible yielding, or perhaps, more probably some degree of yielding, of the earth's figure. The absence from all the results of any indication of a 18.6 yearly tide (according to the same law as the other long-period tides) is not easily explained without assuming or admitting a considerable degree of yielding.

Closely connected with the question of the earth's rigidity, and of as great scientific interest and even of greater practical moment, is the question-how nearly accurate is the earth as a timekeeper? and another of, at all events, equal scientific interesthow about the permanence of the earth's axis of rotation?

Peters and Maxwell, about thirty-five and twenty-five years ago, separately raised the question, how much does the earth's axis of rotation deviate from being a principal axis of inertia? and pointed out that an answer to this question is to be obtained by looking for a variation in latitude of any or every place on the earth's surface in a period of 306 days. The model before you illustrates the travelling round of the instantaneous axis relatively to the earth in an approximately circular cone whose axis is the principal axis of inertia, and relatively to space in a cone round a fixed axis. In the model, the former of these cones, fixed relatively to the earth, rolls internally on the latter, supposed to be fixed in space. Peters gave a minute investigation of observations at Pulkova in the years I84I-42, which seemed to indicate at that time a deviation amounting to about $\frac{3}{40}$ " of the axis of rotation from the principal axis. Maxwell, from Greenwich observations of the years $185 \mathrm{I}-1854$, found seeming indications of a very slight deviation-something less than half a second-but differing altogether in phase from that which the deviation indicated by Peters, if real and permanent, would have produced at Maxwell's later time. On my begging Prof. Newcomb to take up the subject, he kindly did so at once, and undertook to analyse a series of observations suitable for the purpose, which had been made in the United States Naval Observatory, Washington. A few weeks later I received from him a letter referring me to a paper by $\mathrm{Dr}$. Nysen, of Pulkova Observatory, in which a similar negative conclusion as to constancy of magnitude or direction in the deviation sought for is arrived at from several series of the Pulkova observations between the 
years 1842 and 1872 , and containing the following statement of his conclusions :-

"The investigation of the ten month period of latitude from the Washington prime vertical observations from 1862 to 1867 is completed, indicating a co-efficient too small to be measured with certainty. The declinations with this instrument are sub. ject to an annual period which made it necessary to discuss those of each month separately. As the series extended through a full five years, each month thus fell on five nearly equidistant points of the period. If $x$ and $y$ represent the co-ordinates of the axis of instantaneous rotation on June 30,1864 , then the observations of the separate months gave the following values of $x$ and $y$ :-

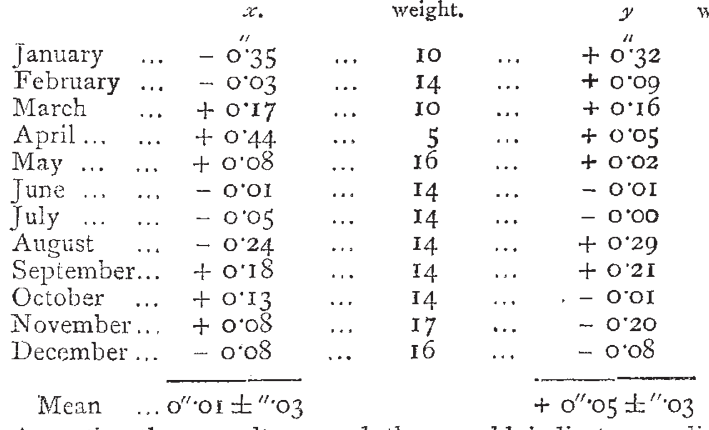

Accepting these results as real they would indicate a radius of rotation of the instantaneous axis amounting, at the earth's surface, to 5 feet and a longitude of the point in which this axis intersects the earth's surface near the north pole such that on July II, I864, it was $180^{\circ}$ from Washington, or $103^{\circ}$ east of Greenwich. The excess of the co-efficient over its probable error is so slight that this result cannot be accepted as anything more than a consequence of the unavoidable errors of observation."

From the discordant character of these results we must not however, infer that the deviations indicated by Peters, Maxwell, and Newcomb are unreal. On the contrary any that fall within the limits of probable error of the observations onght properly to be regarded as real. There is in fact a vera causa in the temporary changes of sea-level due to meteorological causes, chiefly winds, and to meltings of ice in the polar regions and return evaporations, which seems amply sufficient to account for irregular deviations of from $\frac{1}{2}$ " to $\frac{1}{50}$ " of the earth's instantaneous axis from the axis of maximum inertia, or, as I onght rather to say, of the axis of maximum inertia from the instantaneous axis.

As for geological upheavals and subsidences, if on a very large scale of area, they must produce, on the period and axis of the earth's rotation, effects comparable with those produced by changes of sea-level equal to them in vertical amount. For simplicity, calculating as if the earth were of equal density throughout, I find that an upheaval of all the earth's surface in north latitude and east longitude, and south latitude and west longitude, with equal depressions in the other two quarters, amounting at greatest to Io centimetres, and graduating regularly from the points of maximum elevation to the points of maximum depression in the middles of the four quarters, would shift the earth's axis of maximum moment of inertia through $I^{\prime \prime}$ on the north side towards the meridian of $90^{\circ}$ W. longitude, and on the sonth side towards the meridian of $90^{\circ} \mathrm{E}$. longitude. If such a change were to take place suddenly, the earth's instantaneous axis would experience a sudden shifting of but ${ }^{\prime \prime}$ " (which we may neglect) and then, relatively to the earth, would commence travelling, in a period of 306 days, round the fresh axis of maximum moment of inertia. The sea would be set into vibration, one ocean up and another down through a few centimetres, like water in a bath set aswing. The period of these vibrations would be from twelve to twenty. four hours, or at most a day or two; their subsidence would probably be so rapid that after at most a few months they would become insensible. Then a regular 306 days' period tide of II centimetres from lowest to highest would be to be observed, with gradually diminishing amount from century to century, as through the dissipation of energy produced by this tide, the instantaneous axis of the earth is gradually brought into coincidence with the fresh axis of maximum moment of inertia. If we multiply these figures by 3,600 , we find what would be the result of a similar sudden upheaval and subsidence of the earth to the extent of 360 metres above and below previous levels. It is not impossible that in the very early ages of geological history such an action as this, and the consequent 400 metres tide producing a succession of deluges every 306 days for many years may have taken place; but it seems more probable that even in the most ancient times of geological history the great world wide changes, such as the upheavals of the continents and subsidences of the ocean beds from the general level of their supposed molten origin, took place gradually through the thermo-dynamic melting of solids and the squeezing out of liquid lava from the interior to which I have already referred. A slow distortion of the earth as a whole would never produce any great angular separation between the instantaneous axis and axis of maximum moment of inertia for the time being. Considering, then, the great facts of the Himalayas and Andes, and Africa and the depths of the Atlantic, and America and the depths of the Pacific, and Australia, and considering farther the ellipticity of the equatorial section of the sea-level estimated by Capt. Clarke at about $\frac{1}{10}$ of the mean ellipticity of meridional sections of the sea-level, we need no brush from the comet's tail, a wholly chimerical cause which can never have been put forward seriously except in ignorance of elementary dynamical principles, to account for a change in the earth's axis; we need no violent convulsion producing a sudden distortion on a great scale with change of the axis of maximum moment of inertia followed by gigantic deluges; and we may not merely admit, but assert as highly probable, that the axis of maximum inertia and axis of rotation, always very near one another, may have been in ancient times very far from their present geographical position, and may have gradually shifted through ten, twenty, thirty, forty, or more degrees without, at any time, any perceptible sudden disturbance of either land or water.

Lastly, as to variations in the earth's rotational period:You all, no doubt, know how in 1853 Adams discovered a correction to be needect in the theoretical calculation with which Laplace followed up his brilliant discovery of the dvnamical explanation of an apparent acceleration of the moon's mean motion, shown by records of ancient eclipses; and how he found that when his correction was applied, the dynamical theory of the moon's motion accounted for only about half of the observed apparent acceleration; and how Delaunay in 1866 verified Adams's result, and suggested that the explanation may be a retardation of the earth's rotation by tidal friction. The conclusion is that since March I9, 72I B.C., a day on which an eclipse of the moon was seen in Babylon, commencing "when one hour after her rising was fully passed," the earth has lost rather more than $\frac{300 \frac{1}{0}}{0 \sigma} 0$ of her rotational velocity, or as a timekeeper, is going slower by $\mathrm{I} I \frac{1}{2}$ seconds per annum now than then. According to this rate of retardation, if uniform, the earth at the end of a century would, as a timekeeper, be found 22 seconds behind a perfect clock, rated and set to agree with her at the beginning of the century. Newcomb's subsequent investigations in the lunar theory have on the whole tended to confirm this result, but they have also brought to light some re markable apparent irregularities in the moon's motion, which, if real, refuse to be accounted for by the gravitational theory without the influence of some unseen body or bodies passing near enough to the moon to influence her mean motion. This hypothesis Newcomb considers not so probable as that the apparent irregularities of the moon are not real and are to be accounted for by irregularities in the earth's rotational velocity. If this is the true explanation it seems that the earth was going slow from 1850 to $\mathrm{I} 862$, so much as to have got behind by 7 seconds in these 12 years, and then to have begun going faster again so as to gain 8 seconds I862 to 1872 . So great an irregularity as this wonld require somewhat greater changes of sea-level, but not many times greater, than the British Association Committee's reductions of tidal observations for several places in different parts of the world, allow us to admit to have possibly taken place. The assumption of a fluid interior, which $N^{2}$ ewcomb suggests, and the flow of a large mass of the fluid "from equatorial regions to a position nearer the axis," is not, from what I have said to you, admissible as a probable explanation of the remarkable acceleration of rota. tional velocity which seems to have taken place about I 862 ; but happily it is not necessary. A settlement of 14 centimetres in the equatorial regions with corresponding rise of 28 centimetres at the poles, which is so slight as to be absolutely undiscoverable in astronomical observatories, and which would involve no change of sea-level absolutely disproved by reductions of tidal observations hitherto made would suffice. Such settlements must occur from time to time; and a settlement of the amount suggested might result from the diminution of centrifugal force due to 150 or 200 centuries' tidal retardation of the earth's rotational speed. 


\section{SECTION B.}

CHEMICAI SCIENCE.

Opening ADdress by William Henky Perkin, F.R.S., PRESIDENT.

THERE can be no doubt that chemistry and the allied sciences are now being recognised to a much greater extent in this country than in former years; and not only so, the workers at research, though still small in number, are more numerous than they were.

In 1868 , Dr. Frankland, in his address to this section at the meeting at Norwich, commented upon the small amount of original research then being carried on in the United Kingdom ; but, judging from the statistics of the Chemical Society, this state of things became even worse; for in 1868 there were fortyeight papers read before the Society, but in 1872 only twentytwo: Since then, however, there has been a considerable increase in the number; and at the Anniversary Meeting in March last it was shown that the number of communications for the session had risen to sixty-six, or three times as many as in 1872 .

Of course these figures only refer to the Chemical Society; but I think they may be taken as a very safe criterion of the improved state of things, though it would be very gratifying to see much greater activity.

It is also very pleasing to find that the aids to, and opportunities for, research are increasing, because it must be remembered that, in a pecuniary sense, science is far from being its own rewarder at the time its truths are being studied, although the results very often become eventually of the greatest practical value; hence the wisdom of a country encouraging scientific research.

But little, however, has been done in this direction in past years. The grants made for general science by this association and that of the Government of $1,000 \%$. annually to the Royal Society being the most important.

The Chemical Society has also been in the habit of giving small grants for the purpose of assisting those engaged in chemical research. In the future, however, it will be able to do much more than hitherto, One of the original members of the society, Dr. Longstaff, offered in the early part of the year to give $\mathrm{r}, \mathrm{oool}$. provided a similar sum could be raised, the united amount to be invested, and the interest applied for the encouragement of research. I am happy to state that rather more than the required sum has been raised, and it is hoped that it may be still further supplemented.

In addition to the Royal Society grant, the Government have given this year a further annual sum of $4,000 \%$. Of course this is for science generally.

Mr. T. J. Phillips Jodrell has also placed at the disposal of the Royal Society the munificent sum of $6,000 /$. to be applied in any manner that they may consider for the time being most con. ducive to the encouragement of research in physical sciences.

When we consider how much of our science is of a physical nature, we must be grateful for this bequest; and it is to be hoped that these helps will more and more stimulate research in the United Kingdom; and if we have any hope of keeping pace with the large amount of work being now carried on in otber countries we must indeed be energetic.

The employment of well trained chemists in chemical works is now becoming much more general than heretofore, especially on the Continent, where in some cases a considerable staff is employed and provided with suitable appliances, \&c., for the purpose not only of attending to and perfecting the ordinary operations which are in use, but to make investigations in relation to the class of manufacture they are engaged in. A conviction of the necessity of this is gaining strength in this country, though not so quickly as might be desired; nevertheless these things are encouraging.

With reference to the progress of chemistry and what have been the fruits of research of late years, it will be impossible for me to give even a general outline, the amount of work being so large; in fact, to recount the list of investigations made during the past year would take up most of the time at my disposal.

Amongst the most interesting, perhaps, are those relating to isomerism, especially in the aromatic series of organic bodies; and it is probable that a more intimate knowledge of this subject will be found of really practical value.

As I am unable to give an account of the work done during the past year on account of its extent and diversity, I propose to refer to some of the practical results which have already accrued from organic chemistry, as a plea for the encouragement of research; and those $I$ intend to speak of are of special interest also on account of their close connection with the textile manufactures of Great Britain. I need scarcely say I refer to the colouring matters which have been obtained from the products found in tar.

It was in 1856 , now twenty years since, that this industry was commenced by the discovery of the "mauve" or "aniline purple," and it may be of interest to state that it was in Scotland in the autumn of the same year that the first experiments upon the application of this dye to the arts of dyeing and calico-printing were made at Perth and Maryhill.

I need scarcely remind you of the wonderful development of this industry since then, seeing we now have from the same source colouring matters capatile of producing not only all the colours of the rainbow, but their combinations. I wish now, however, briefly to refer to the date and origin of the products which have served to build up this great industry.

It was in 1825 that Faraday published in the Philosophical Transactions his research on the oily products separated in compressing oil-gas, and described a substance he obtained from ita volatile colourless oil-which he called bicarburetted hydrogen. Mitscherlich some years afterwards, obtained the same substance from benzoic acid, and gave it the name it bears, viz. "Benzol." This same chemist further obtained from benzol nitrobenzol, by acting upon it with nitric acid. Zinin afterwards studied the action of reducing agents upon nitrobenzol, and obtained "aniline," which he at that time called benzidam.

Again, Pelletier and Walter discovered the hydrocarbon toluol in 1837 . Deville produced its nitro-compound in 1841 , and Holmann and Muspratt obtained from this "toluidine," by the process used by Zinin to reduce nitrobenzol.

I might mention other names in connection with these sub. stances, such as Runge, Unverdorben, \&c., but I would now ask, did any of these chemists work at these subjects for the hope of gain? was it not rather from the love of research, and that alone? and now these products, which were then practically useless, are the basis of the aniline colours. But to go further: Doebereiner a long while ago obtained from alcohol a substance which he called "light oxygen ether," now known as aldehyd. Gay-Lussac produced iodide of ethyl in 1815. Dumas and Peligot discovered the corresponding substance iodide of methyl in 1835 ; but, as in the cases I have previously referred to, these bodies had no practical value, and were never prepared but in the laboratory. Hofmann, in his researches on the molecular constitution of the volatile organic bases, in 1850 , discovered the replacement compounds of aniline containing alcohol radicals.

All these compounds have now been manufactured on the large scale, and used in the further development of the industry of these aniline colouring-matters.

Other substances might be mentioned, but I think these are sufficient to show how the products of research which, when first discovered and for a long period afterwards, were of only scientific interest, at last became of great practical value ; and it is evident that had not the investigations and discoveries $I$ have referred to been made as they were solely from a love of science, no aniline colours would now be known.

The colouring-matters I have hitherto spoken of are nitrogenous, and derived from benzol and its homologues; there are a few others, however, of the same origin which contain no nitrogen, but they are of secondary importance.

I now pass on to another class of colouring-matter which is obtained from anthracene, a coal-tar product differing from benzol and toluol in physical characters, inasmuch as it is a magnificent crystalline solid.

The first colouring-matter derived from anthracene which I wish to draw your attention to is alizarin, the principal dyeing agent found in the madder-root. This substance was for a long time supposed to be related to naphthaline, inasmuch as phthalic acid can be produced from both of them; and many were the experiments made by chemists in this direction; it was not, however, until 1868 that this was proved to be a mistake, and its relationship to anthracene was discovered by Graebe and Liebermann, who succeeded in producing this coal-tar product from the natural alizarin itself.

Having obtained this important result, they turned their attention further to the subject, hoping to find some process by which alizarin could be produced from anthracene; in this they were soon successful.

The discovery of the artificial formation of alizarin was of great interest, inasmuch as it was another of those instances which have of late years become so numerous, namely, the 
formation of a vegetable product artificially, but the process used by Graebe and Liebermann was of little practical value on account of the difficulty and expense of working it.

Having previously worked on anthracene derivatives, it occurred to me to make some experiments on this subject, which resulted in the discovery of a process by which the colouringmatter could be economically produced on the large scale Messrs. Caro, Graebe, and Liebermann at about the same time obtained similar results in Germany ; this was in 1869. Further investigation during the same year yielded me a new process, by which "dichloranthracene" could be used in place of the more costly product anthraquinone, which was required by the original processes. I mention this as most of the artificial alizarin used in this country up to the end of 1873 , and a good deal since, has been prepared by this new process.

It was observed that when commercial artificial alizarin prepared from anthraquinone, but more especially from dichloranthracene, was used for dyeing, the colours produced differed from those dyed with madder or pure alizarin, and many persons therefore concluded that the artificial colouring-matter was not alizarin at all. This question, however, was set at rest by separating out the pure artificial alizarin from the commercial product and comparing it with the natural alizarin, when it was found to produce exactly the same colours on mordanted fabrics, to have the same composition, to give the same reactions with reagents, and to yield the same products on oxidation.

But whilst examining into this subject it was found that a second colouring-matter was present in the commercial product, and in somewhat large quantities, especially when dichloranthracene had been employed in its preparation, and to this was due the difference in shade of colour referred to.

This substance, when investigated, was found to have the same composition as "purpurin," also a colouring-matter found in madder, but of very little value on account of the looseness and dulness of some of the colours it produces. This new substance, being derived from anthracene, was named anthrapur. purin; unlike its isomer purpurin, however, it is of great value as a colouring-matier. I do not think I shall be going beyond the results of experience if $I$ say it is of as great importance as alizarin itself; with alumina mordants it produces reds of a more scarlet or fiery hue than those from alizarin. In fact, so fine are the colours produced that, with ordinary aluminamordants on unoiled cotton, it gives results nearly equal to Turkey-red produced with madder or garancine, and I believe the rapid success of artificial alizarin was greatly due to its presence. Most of that consumed at first was for Turkep-red dyeing, and the colours were so clear and brilliant that it was mostly used in combination with madder or garancin, to brighten the colours produced by these natural products.

The purple colours anthrapurpurin produces with iron mor. dants are bluer in shade than those of alizarin, and the blacks are very intense. Its application is practically the same as alizarin, so that they can be used in combination.

As noted just now, the commercial product called "artificial alizarin" first supplied to the consumer was always a mixture of alizarin and anthrapurpurin, and various mixtures of these two colouring-matters are still sent into the market; but owing to the investigations that have been made, and the study and attention that have been given to it by manufacturers, nearly pure alizarin and anthrapurpurin are also sent into the market; the first being known as "blue shade alizarin," and the second as red or "scarlet alizarin."

The formation of anthrapurpurin in the manufacture of alizarin may to some extent be said to have arisen from a want of knowledge of the true conditions required for the production of the latter.

It is now well known that alizarin is a dioxyanthraquinone, or, in other words, anthraquinone, in which two atoms of hydrogen are replaced by hydroxyl.

$$
\underbrace{\mathrm{C}_{14} \mathrm{H}_{8} \mathrm{O}_{2}}_{\text {Anthraquinone. }} \quad \underbrace{\mathrm{C}_{14} \mathrm{H}_{6}(\mathrm{HO})_{2} \mathrm{O}_{2}}_{\text {Alizarin. }}
$$

If we want to introduce hydroxyl into a compound, there are several processes which can be used, but I will only refer to those connected with the history of this colouring matter.

The first process which I will refer to has been used by chemists for a long period. It consists in first replacing the hydrogen by bromine, and then treating the resulting body with potassic or other metallic hydrate; and according as one, two, potassic or other metalic hydrate; and according as one, two so on its removal by the metal of the metallic hydrate, a compound containing a corresponding number of atoms of hydrogen replaced by hydroxl is obtained.

Graebe and Liebermann acted upon this principle in their experiments on the artificial formation of alizarin ; and as it was necessary to replace two atoms of hydrogen in anthraquinone, they first of all prepared a dibrominated derivative, called dibromanthraquinone,

$$
\mathrm{C}_{14} \mathrm{H}_{6} \mathrm{Br}_{2} \mathrm{O}_{2}
$$

By decomposing this with potassic hydrate at a high temperature, they obtained a violet-coloured product, which, when acidified to remove the alkail, gave a yellow precipitate of alizarin,

$$
\mathrm{C}_{14} \mathrm{H}_{6}(\mathrm{HO})_{2} \mathrm{O}_{2} \text {. }
$$

The second process I wish to speak of for the replacement of hydrogen by hydroxyl in a compound is by converting it into a sulpho-acid (usually by means of sulphuric acid), and subsequently decomposing this with potassic or other hydrate; and according as a mono- or disulpho-acid is employed, it yields on decomposition a compound with one or two atums of hydrogen replaced by hydroxyl.

The discovery of sulpho acids of anthraquinone, and their use in place of the brominated derivative originally employed by Graebe and Liebermann, constituted the great improvement in the manufacture of alizarin already referred to.

From what has just been stated, it was naturally supposed that a disulpho-acid of anthraquinone would be required to produce alizarin; and this was believed to be the case for some time; but further experiments have proved it to be a mistake, and shown that the monosulpho-acid is required to produce alizarin, the disulpho-acid yielding anthrapurpurin.

But how are we to explain this apparent anomaly? It would. take up too much time to enter into a discussion respecting the constitution of the sulpho-acids of anthraquinone in reference to the position of the $\mathrm{HSO}_{3}$ groups. I will therefore confine my remarks to their decomposition.

Monosulphoanthraquinonic acid,

$$
\mathrm{C}_{14} \mathrm{H}_{7}\left(\mathrm{HSO}_{3}\right) \mathrm{O}_{2} \text {, }
$$

when heated strongly with caustic alkali, as potassic or sodic hydrate, decomposes in the ordinary way, and we get "monoxyanthraquinone,"

$$
\mathrm{C}_{14} \mathrm{H}_{7}(\mathrm{HO}) \mathrm{O}_{2} \text {, }
$$

which is a yellow body possessing no dyeing properties. On further treating this, however, with caustic alkali it changes, being oxidised, and yields alizarin,

Disulphoanthraquinonic acid,

$$
\mathrm{C}_{14} \mathrm{H}_{6}(\mathrm{HO})_{2} \mathrm{O}_{2} \text {. }
$$

$$
\mathrm{C}_{14} \mathrm{H}_{6}\left(\mathrm{HSO}_{3}\right) \mathrm{O}_{2} \text {, }
$$

when subjected to the influence of caustic alkali, at first changes into an intermediate acid,

$$
\mathrm{C}_{14} \mathrm{H}_{6}(\mathrm{HO})\left(\mathrm{HSO}_{3}\right) \mathrm{O}_{2}
$$

and then into a dioxyanthraquinone,

$$
\mathrm{C}_{14} \mathrm{H}_{6}(\mathrm{HO})_{2} \mathrm{O}_{2} \text {, }
$$

now known as "isoanthraflavic acid"--a substance having the same composition as alizarin, but being only an isomer of that body, and possessing no affinity for mordants; like monoxyanthraquinone, however, when further heated with alkali, it becomes oxidised and yields a colouring-matter, which is "anthrapurpurin,"

$$
\mathrm{C}_{14} \mathrm{H}_{5}(\mathrm{HO})_{3} \mathrm{O}_{2} \text {. }
$$

Looking at these reactions, it appears rather remarkable that Graebe and Liebermann should have succeeded in preparing alizarin from dibromanthraquinone. It can only be explained on the assumption that the hydrogen atoms replaced in the disulpho-acid are different in position to those replaced in the dibromanthraquinone; and of course it is possible that a disulpho-acid isomeric with that now known may be discovered that will yield alizarin as a first product on treatment with alkali.

In the reaction which takes place when monoxyanthraquinone or isoanthraflavic acid become oxidised and change into alizarin and anthrapurpurin, nascent hydrogen is formed; and this causes a reverse action to take place, ordinary anthraquinone or its hydrogen derivative, being formed, and a loss of colouringmatter resulting. A small amount of potassic chlorate is now used with the caustic alkali, just sufficient to overcome the 
reducing action which has resulted in an increased yield of colouring.matter, the percentage obtained being now not very much below the theoretical quantity.

When the process for making commercial artificial alizarin by treating anthraquinone with sulphuric acid was first adopted, the product from that treatment was a mixture of the mono" and disulpho-acids of anthraquinone. Consequently the colouringmalce a mixture of alizarin and anthrapurpurin; and the reason why dichloranthracene, when used in place of anthraquinone, yields a product very rich in anthrapurpurin, is on account of the readiness with which it forms a disulpho-acid of dichloranthracene which afterwards changes into the disulpho-acid of anthraquinone.

At first it was supposed by many that the quantity of coal-tar produced would not yield a sufficient supply of anthracene for the manufacture of artificial alizarin. Experience has, however, proved that this supposition was groundless, as now the supply is greater than the demand.

Moreover some very interesting experiments have lately been made, by which anthraquinone and its derivatives have been obtained without the use of anthracene. The most interesting are those in which phthalic anhydride is employed with benzolic derivatives; for example, this anhydride gives with hydroquinone a colouring-matter having the same composition, as well as most of the other properties of alizarin. It is called quinizarin, Baeyer and Caro have also obtained from phthalic anhydride and phenol oxyanthraquinone; and by using pyrocatechin in place of phenol they got alizarin itself.

Although these products have not been obtained in sufficient quantities by these processes to be of any practical value, we do not know what further research may do. Already one of the substances used is being prepared on the large scale for the manufacture of that beautiful colouring-matter "eosine ;" I refer to phthalic anhydride.

Now with reference to the origin of the products which are used for the manufacture of artificial alizarin. We find the first researches made in reference to anthracene were by Dumas and Laurent in 1832 ; subsequently Laurent further worked upon this subject, and obtained, by the oxidation of this hydrocurbon, a substance which he called anthracenuse; he also obtained dichloranthracene. Dr. Anderzon also made an investigation on anthracene and its compounds in 1863, and assigned to it its correct formula; he re-examined its oxidation product, which Laurent called anthracenuse, and ramed it oxyanthracene, this substance we now know as anthraquinone.

All these substances were without any practical value until I868; but we now find them of the greatest importance, and used in very large quantities.

But to bring out more clearly the practical importance of these fruits of research, it will be well perhaps to see what has been their infuence on the colouring-matters which were in use before them, and also the extent of their present consumption.

The influence of the so-called aniline colours on the old colouring matters, has been remarkably small. It is true that at first magenta had a depreciating influence upon cochineal; but this has passed away, and now the consumption of that dye is as great as ever; certainly its price is much lower than it used to be; but this is due to a variety of causes, especially the great increase in the cultivation of the insect at Teneriffe. And perhaps this want of influence is not so very remarkable, when $\mathrm{w}$ e consider the aniline colours are entirely new products, differing in composition and properties from the old colouring-matters, \&c., and therefore could only displace them to a certain extent.

But whilst this is the case the aniline colours have been more and more used, until at present it is computed that their annual sale in the United Kingdom and on the Continent exceeds $2,000,000 \%$. This is probably due to new applications and increase of trade.

When, however, we come to consider the influence of the anthracene colours alizarin and anthrapurpurin, more generally known as "artificial alizarin," we find we have a very different tale to teil.

Here, in the case of alizarin, we have a competition not between two colouring-matters, but the same from different sources; the old source being madder-root, the new one coal-tar. And when we introduce the consideration of anthrapurpurin, which produces such magnificent reds, much brighter than alizarin or ordinary purpurin, we see we have not only a replacement but an improvement, so that these new colouring-matters throw the old ones into the shade. The products being purer, the clear. ing processes for goods dyed with them are also necessarily easier and simpler.

It will be interesting to examine into the statistics of the madder and garancine trade in a brief manner, to see what has been the influence of artificial alizarin on their consumption. The following figures are mostly calculated from the Board of Trade returns.

During the ten years immediately preceding the introduction of artificial alizarin the average annual imports of madder into the United Kingdom were 15,292 tons, and of garancine 2,278 tons. Estimating the value of the former at $2 l .2 s .6 d$, and the latter at $8 l$. per cwt., which were about the average prices during that period, the annual value in round numbers was about one nillion sterling.

The introduction of artificial alizarin has, however, so influa enced the value of madder that its price is now less than onehalf; and thus a saving of over half a million sterling per annum has been effected to the manfacturers of the United Kingdom, one half of which may be put down to Glasgow.

So much for its effect in reducing prices; but what has been its infuence on the consumption of these dye-stuffs?

I have already stated the average quantity of these substances imported per annum prior to the discovery of the artificial pro. duct, and will now compare it with the imports of last year and this. That for the present year of course is an estimated quantity, and calculated from the returns for the first seven months.

$$
\begin{aligned}
& \text { Average annual imports. }
\end{aligned}
$$

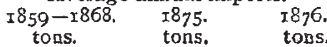

$$
\begin{aligned}
& \begin{array}{lrrrr} 
& \multicolumn{1}{c}{\text { tons. }} & \text { tons. } & \text { tons. } \\
\text { Madder } & \ldots . . . . & 15,292 & 5,014 & 3,653 \\
\text { Garancine } & \ldots . . . & 2,278 & 1,293 & 813
\end{array}
\end{aligned}
$$

These numbers speak for themselves.

The money value, which was formerly $\mathbf{1}, 000,000 \%$ per annum, is now, calculating from the estimated quantily for this year, only 138 , I05 $l$., say $140,000 l$. taking garancine at 4l. per cwt. and madder at $\mathrm{I} l$. per cwt., prices slightly in excess of their present value.

At the present prices the cultivation of madder-roots is unremunerative, so that it is to be expected that madder growing will soon be a thing of the past, thousands of acres of land being at the same time liberated for the growth of those products we can. not produce artificially, and without which we cannot exist. The quantity of madder grown in all the madder-growing countries of the world prior to 1868 was estimated to be 70,000 tons per amum, and at the present time the artificial colour is manufactured to an extent equivalent to 50,000 tons, or more than two-thirds of the quantity grown when its cultivation had reached its highest point.

I might have referred to other subjects besides the coal-tar colours which have resulted from scientific research ; but I know of no other of such interest and magnitude. From the brief history I have given we see that the origin of these colouring matters is entirely the fruit of many researches made quite independently by different chemists, who worked at them without any knowledge of their future importance ; and on looking at the researches which have thus culminated in this industry, it is interesting to notice that many, if not most of them, were conducted for the purpose of elucidating some theoretical point.

These facts certainly ought to be a great encouragement to chemists, and stimulate them to greater activity. It would be very pleasing to see more work emanating from the chemical schools of the United Kingdom; and I think no student should consider his chemical curriculum finished until he has conducted an original research. The knowledge obtained by a general course of instruction is of course of very great value, but a good deal of it is carried on by rule; in research, however, we have to depend upon the exercise of our judgment, and in fact of all our faculties; and a student having once conducted even one investigation, under the guidance of an efficient director, will find that he has acquired an amount of experience and knowledge which will be of the greatest value to him afterwards.

It is hoped these remarks will encourage young chemists patiently and earnestly to work at whatever subject they may undertake, knowing that their results, although sometimes appa. rently only of small interest, may contain the germ of something of great scientific or practical importance, or may, like a keystone in an arch, complete some subject which before was fragmentary and use]ess. 


\section{SECTION C.}

GEOLOGY.

THE Duke of Argyll read a paper On the Physical Structure of the Highlands, in connection with their Geological History. He said :--The questions dealt with by geological science have now become so vast and various that no one district of country can be expected to furnish illustrations of more than a very few of them. The West of Scotland, in the capital of which we are now assembled, is not rich in deposits which illustrate the passage of animal life from the types which have become extinct to those which are of more modern origin and which still survive. No bone caverns have been discovered of importance, and, with one exception, even our river gravels and $\epsilon$ stuarine deposits have not been especially productive. That exception is, indeed, a feature. It was in this valley of the Clyde that the late Mr. Smith, of Jordanhill, first discovered those indications of Antarctic climate recently prevailing, which have ever since constituted a large and importan branch of geological inquiry, and the full interpretation of which still presents some of the most curious problems with which we have to deal. But our Palæozoic areas, except the Coal Measures, are to a large extent singularly unfossiliferous; neither the Scottish Oolite nor Lias have yielded any remarliable additions to the curious fauna of which in England and elsewhere they have yielded abundant specimens. But, on the other hand, perhaps no area of country of equal extent in any quarter of the world presents more remarkable phenomena than the $W^{\top}$ est of Scotland in connection with those causes of geological change which have determined the form of the earth's surface, and have given to its physical geography those features of variety and beauty which are the increasing delight of civilised and instructed men.

We cannot descend the course of this river Clyde to the noble estuary in which it ends, without having presented to us mountain outlines and an intricate distribution of sea and land which raise questions of the highest interest, and of the greatest difficulty. From the northern shores of that estuary to Cape Wrath, in Sutherland, the country is occupied mainly by rocks of the Silurian age, but so highly crystalline as to be almost wholly destitute of fossils, and so upheaved, twisted, contorted, and folded into a thousand difterent positions that, except in one great section, it is most difficult to trace any persistent succession of beds. It is one great series of billowy undulations, traversed by glens and valleys, some of which are high above the level of the sea, but many of which are now so deeply submerged that the ocean is admitted far into the bosom of the hills. These glens and valleys lie in many different directions, but there are so many with one prevalent direction as to give a general character to the whole-a direction from north-east to southwest, or parallel to the prevalent strike of the Silurian rocks. The shapes of the hills and mountains are not by any means wholly without relation to geological structure, because in a thousand cases the sloping outlines will be found to be determined by the inclination of the beds, and the precipitous or steeper outlines to be determined by the upturned or broken edges. In like manner there are cases where a crumpled or knotted outline is the index of beds deeply folded and counteracted along antilineal axes; but, nevertheless, there are also innumerable cases where no such relation can be traced, where the mountains seem to have been cut off some solid mass, all the rest of which has been removed by some agency which left these great fragments standing by themselves, and of which the contours cut across the lines of the structure at every variety of angle.

Along the whole western face of this country it is guarded from the open ocean by an archipelago of islands, some of which are separated from the mainland vy submerged valleys no broader than those which separate one hill from another in the inland glens. Many of these islands are wholly occupied by the débris and the outbursts of extinct volcanoes. The mountains which are thus composed bear in many cases the characteristic forms of lava streams, but many others are not readily distinguishable in outline from the mountains of wholly different material which are near them. They reach the same general average level of height, here and there rising into peaks very similar to others of a widely different age and of a widely different material. More. over, all the islands partake largely of the general character of the mainland in having their deeper valleys submerged, and in being thus deeply indented by arms of the sea similar to those whicu give its peculiar outline to the adjacent coasts.

It may serve to bring more vividly before you the facts of the physical geography of the country (for which it is one of the duties of geologists to account if they can) if I give you some statistic I facts affecting the single county of Aryyll, which begins on the northern shore of the Firth of Clyde. Following the coastline of that county from the head of Loch Long, wbich is its southern and eastern boundary, to Loch Aylort, which is its northern and western boundary, and, including its islands, we find it measures no less than 2,289 miles in length, of which about 840 represent the sinuosities of the mainland, and $\mathbf{I}, 449$ represent the coast-line of its larger islands. There are, besides, valleys, which are now inland, and are occupied by fresh-water lakes, which evidently at a recent period were arms of the sea, and these represent a further line of coast measuring 276 miles. There are eleven principal arms of the sea, each of them measuring from one to thirty-six miles in length. Two of these arms of the sea exceed the roo fathoms line in depth-Loch Fyne and the Linnhe Loch; and it is very remarkable that these deep soundings do not occur near the points where these lochs join the more open sea, but, on the contrary, far up their course or bed among the mountains. The ridges dividing these and the other valleys vary in elevation from hills of very moderate height to the ranges of Cruachan, which immediately beyond the boundary of the country culminates in Ben Nevis, which rears its head almost on a level with Ben Macdhui, now ascertained to be the highest summit in the British Isles. But no statistics can give an idea of the intricacy with which sea and land are interfolded on the western coasts comparable with that which is gained by some of the many beautiful views that abound on the heights in the vicinity of Oban, whence the visitor can command the entrance of Ioch Etive, with the course for many miles of the Linnhe Loch, of the Sound of Mull, the Sound of Kerrera, and the Firth of Lorne.

Now, the question naturally arises-to what geological ages and to what geological causes do we owe in its main features this curious distribution of land and sea? I say in its main features, because, of course, the more superficial sculpturing of every mountainous country is undergoing incessant modification, and this modification may have been, and probably has been, very considerable indeed, in the times which, geologically speaking, belong to the existing age; but the question I put has reference to the epoch of past time when the main oullines of hill and valley were determined, when the great mass of the country (which has been, I believe, correctly identified as composed of metimorphosed Silurian beds) was elevated into the various mountain chains which now constitute its characteristic leatures.

If the question had been asked some five-and-twenty years ago I should have said that the evidence pointed to an age of great geological antiquity, for the central group of highland mountains was in some shape like that in which we see them. All round the edges of the country there are the remains of the Old Red Sandstone, which often fit into the contour of the valleys and have left fraoments in nooks and recesses of the hills. It would almost seem as if they had been the shores of the seas and great lakes in which that great system of deposit was laid down; and that they had lifted their heads above those waters in forms not wholly unlike those in which we now see them. The total absence over almost the whole country of any other or later rocks, the absence among the débris of any material other than that of which the hills are themselves composed, would seen to confirm the same general conclusion. Some doubt, however, may seem to have been thrown on this conclusion, since it has become certain that it cannot be true of, at least, one district of our western mountains, which is, nevertheless, closely rilated to all the rest, havin : the same general elevation, partaking of the same general trend of coast-lines, cut up by similar valleys, and fitting into the same contours of denudation.

The district to which I refer is that of the volcanic islands which stretch from the south end of Mull to the north end of Skye. Since the discovery which $I$ was fortunate enough to make in $185 \mathrm{I}$ of the leaf-beds in $\mathrm{Mull}$, it has become clearly ascertained that these islands are the remains of volcanoes of that geological age to which an ever-increasing interest seems to attach-that middle age of the great Tertiary division of geological time to which Lyell gave the name of Miocene. The mountains of Mull and of Eigg and of Rona and of Skye, in all their valleys and intricate lines of coast, have unquestionably an origin later than the Miocene-how much later is the question of physical geography which geologists are called to solve. It is possible, indeed, to suppose that the hills of the mainland might be of a very different age from those of the adjacent islands, and against this, until some two years ago, there would have been nothing to advance except the suspicious similarity and adjust. 
ment between the two groups, the coincidence of their outlines, and of the way in which they had been cut and carved; but the admirable researches of Mr. Judd have, in 1874 , brought one little fact to light which speaks volumes for the enormous changes which must have taken place since the volcanoes of the Miocene over a portion at least of the Highland area, and which may therefore have taken place over the whole of it. The land upon which the Miocene vegetation flourished and upon which the lava streams of the volcanoes were poured out, seems to have been for the most part a land consisting of Cretaceous and Secondary rocks. The fragments of that country which remain are generally consistent with the supposition that they were deposited in a sea which washed round the bases of the Highland mountains, but which never covered them.

Like the fragments of the Old Red Sandstone, the remains of the Secondary rocks lie along the margins and fringes of the Silurian hills; but Mr. Judd has made the startling discovery of an outlier of the whole series of the Secondary rocks, including representative beds of the Trias, Lias, Green Sand, and Chalk, togrether with deposits, probably lacustrine-all lying on the top of one of the mountains of metamorphic gneiss which constitute the district of Morven. This fragment has been preserved by having been covered by a sheet of lava from some great neighbouring volcanic centre, the position of which is indicated by Ben More in Mull ; but the mass of volcanic trap which was covered up and preserved this relic of the Cretaceous land is itself a fragment occupying the top of a mountain of gneiss separated from the remainder of the sheet of lava to which it belongs by deep valleys precisely similar to those which divide the hills from each other throughout the whole area of the Highlands. The position of an outlier of the Cretaceous rocks on the summit of a moun. tain of gneiss is rendered still more curious by the circumstance that in that position the beds are not tilted, or in any way apparently disturbed. They are arranged horizontally, as if the ocean floor on which they were deposited had occupied that level, or as if its deposits had been lifted up over so large an area that any small section of that area could retain its original horizontality. The lower Silurian gneiss beds on which these Secondary deposits have been laid are violently twisted and contorted, and this structure must have belonged to them when they constituted the Boor of the Cretaceous sea; the position of the Miocene busalts capping the Secondary deposits proves that the whole mountain, as a mountain, is of later date than the Miocene age -how much later we cannot tell, and thus that the causes of geological change which have cut up the country into its present form, though they doubtless began in very remote epochs, have at least been prolonged into a comparatively late age in the history of the globe.

It would, I think, be affectation to pretend that our science enables us to follow with any thing like distinctness of conception the exact nature and sequence of operations which through such a vast lapse of time have brought about the final result, but I believe in something like the following outline of events :-

First, that subsequent not only to the consolidation, but probably also to the metamorphism of the Lower Silurian deposits, the whole area of the Western and Central Highlands became an area of that kind of disturbance which arose from lateral pressure, due to secular cooling, and consequent contraction and subsidence of the crust of the earth. Second, that the crumpling, contortion, and tilting of the Silurian beds which we now see, arose from that disturbance. Thirdly, that then wert determined those great general lines of strike running from south-east to northwest which are to this day a prominent feature in the physical geography of the country. Fourthly, that during that period of disturbance, and as part of the movement which then took place, the disturbed rocks fell inwards upon materials at a great heat, which rose in a pasty state along lines of least resistance, and thus came to occupy various positions sometimes intercalated among the sedimentary beds. Fifihly, that to this period, and to this method of protrusion, we owe some at least of the measures of granitic material which are abundant in the Highlands in particular; that to this period belon:s the porphyritic granites on the north shores of Loch Fyne. Sixthly, that during the later ages of the Palæozoic period volcantc action bruke out at various points, accompanied by great displacement ard dislocation of strata, and that to this, with the denudation which followed, we owe much of the very peculiar scenery of the south-western coasts, especially in the district of Lorne, in Argyllshire. Seventh, that we have no proo that the Central Hirnlands were ever under the seas which laid down the deposis of the later Palreozcic age. Eighth, that such evidence as we have, points rather to the conclusion that they were not under such seas, since such fragments as remain of the Old Red and of the Carboniferous rocks appear to have been deposited round the bases and in the marginal hollows of the Silurian hills. Ninth, that, in like manner, we have no evidence that the great mass of the Central or. Western Highlands were ever under the seas of the Secondary ages, which, on the contrary, appear to have deposited their sediment upon an area outside of, but probably surrounding, the area of these Central Highlands, and certainly upon those north-eastern and western flanks. Tenth, that the whole area of the Inner Hebrides and of the water dividing them, together with some portion of the mainland, as in Morven, was an area occupied by Secondary rocks. Eleventh, that in the Teriary ages-probably in the Eocene and certainly in the Miocene---those rocks formed the bases of a great land of unknown extent, very probably extending for a great distance both to the east and west of the present coasts of Scatland and embracing the north of Ireland. Twelth, that this country became in the Miocene age, and possibly earlier, the scene of great volcanic outbursts, which covered it with vast sheets of lava and broke up its Sedimentary rocks with every form of intrusive plutonic matter. Thirteenth, that later in the Tertiary periods and perhaps as late as the Pleíocene, this volcanic country was itsel broken up by immense subsidences and upheavals, giving both occasion and direction to the agencies of denudation and to enurmous removal of material. Fourteenth, that this Tertiary country had been thus broken up and nothing but its iragments left when the glacial epoch began, and that the main outlines of the country as we now see it had been already determined when glacial conditions were established. Fifteenth, that thus the work of the glacial period has been simply to degrarte and denude pre-existing hills and to deepen pre-existing vallevs. Sixteenth, that durixg the glacial epoch there was a subsidence or land to the depth of at least 2,000 feet above the level of the present sea, and again a re-elevation of the land to its present level. Seventeenth, that this re-elevation has not restored the laind to the level it stood at before the subsidence began; but has stopped greatly short of it, and that the deep arms of the sea, or lochs, which intersect the country and some of the deeper fresh-water lakes, such as Loch Lomond, are the valleys still submeryed which at the beginning of the glacial epoch were high above the sea and furrowed in flanks of loftier mountains; that during the glacial period the work of denudation and degra. dation was done, and done only, by ice in the three well-known forms-first, of true glaciers descending mountain slopes; second, ot icebergs detached trom the termination of these glaciers where they reached the sea; and third, by floe or surface ice driven by currents which were determined in direcion by the changing contours of tine land during the processes of submersion and reelevation.

It would be impossible on this occasion to illustrate or support these variuus propositions by going into the evidences on which they rest; but as those of them which relate to the operations of the glacial epoch express a decided opinion upon questions now involving much dispute, I must say a lew words in explanation or detence of that oplnion.

It will be seen that I disbelieve altogether in this theory of what is called an ice-cap, or, in other words, I hold that there is no evidence that there ever existed any unversal mantle of ice hisher or dee. er than all the existing mountans, covering them and moviog over them from distant wesierin reglons.

In the first place, this theory presupposes conicitions of climate which mast have prevailed universaily over the whole worthern hemisphere, whereas over a yreat portion of that hemisphere, west of a certam meridian on the American continent, all traces of yeneral glaciation and of any general distribuition of erraics aisappear. In the second place, the theury assumes tirat masses of ice lying upos the surface of the tarth mure than mountain deep, would have a proper mution of 1 ts uwn capable of overcoming the friction not only of rough level surfaces, but even of the sitepest gradients, for which motion no adequate cause has been assigned and which has never been proved to be this natural consequence of any known force as to be consisient with the physical properues of the material on which it is supposed to have acted. In the third place, as a matter of fact, thite does not now exist anywhere on the klobe masses of ice which can be proved to have any motion of this kind or to be suoject to furces capable of driving and propelling it $i n$ the marner and with the effects which the theory assumes. The case of Greenland, which is often referred to as an example, does not present phenomena at all similar to those attributed to 
the ice-sheet. In the fourth place, all phenomena of glaciation which are exhibited on the mountain ranges, including the distribution of erratics, can be adequately accounted for by the three conditions or forms of moving ice which have been above enumerated, and all of which are now in actual operation on the globe-namely, ice moving, not up, but down mountain slopes by the force of gravitation, and ice floated by water and driven by currents, as icebergs or as floes. In the fifth place, these phenomena of glaciation are essentially different from those which would result from the motion of a universal ice-sheet, supposing it to have existed, and supposing it to have had the (impossible) motion which has been ascribed to it. In the sixth place, that, in particular, the mode in which erratics are distributed and the peculiar position of perched blocks are demonstrative of the action, not of solid, but of floating ice; whilst the surfaces of rock which have escaped glaciation on one side and retain the deepest marks of it upon another side, are equally demonstrative of exposure to moving ice, under conditions which did not enable it to fit into the inequalities of surface over which it passed. In the seventh place, the phenonena seem to me to prove that some of the very heaviest work done by ice has been towards the close of the glacial epoch, when the land was emerging again from out of a glacial sta, and when all the currents of that sea, loaded with bergs and floes, were determined entirely by the outlines of the rising land. In regard to the much-disputed question of the glacial origin of lake-basins, the conchusion to which I have come is one which to some extent reconciles antagonistic views. I do not indeed believe that glaciers can ever dig holes deep under the average slope of the surface down which they move, but on the other hand they are the most powerful of all abrading agents in deepening their own bed and cutting away the rocky surfaces which lie beneath them. If valleys thus deepened by the long work of glaciers and glacier streams are afterwards submerged along with the whole country in which they lay, and if that submergence is accompatied by partial and unequal rates of subsidence, they would inevitably become hollows into which the sea would enter, or in which fresh waters would accumulate. In this sense and in this way it can hardly admit of a doubt that those lakes, which are nothing but submerged valleys, are due in part to glacial action, although the other half of the causation on which they depend is to be sought in the subterranean action of subsidence.

In conclusion, I would observe that although the fact of a great subsidence and a re-elevation of the land during the glacial epoch has been generally aumitted to be one of the facts of which there is the clearest evidence, it is nevertheless a fact of which all the conditions and all the consequences have been most imper. fectiy recognised. Withont venturing to go so far back as to imacine the process of subsidence and submergence, let us only think for a moment of that movement of re-elevation which has certainly been one of the very latest of the great movements of geological change. If it took place very gradually and very slowly, it necessitated the supposition that every inch of our mountain surfaces, up to at least 2,000 feet, has been in succession exposed to the conditions of a sea beach. Yet where are the marks upon them of such conditions? We may suppose such marks to have been generally obliterated by later sub-aërial denudation; but against this is to be set the fact that the position and distribution of perched blocks and other erratics deposited by floating ice demonstrates in my opinion that very little indeed of such denudation has taken place since they were placed where we now see them.

I could take any of you who are interested in this question to a precipitous hill near Inveraray, some I, 200 feet above the level of the sea, from the top of which you can look down on the masses of transported rock stranded upon its sides and base, precisely as one might look down from the top of some dangerous reef in the present ocean upon the delbris of a whole navy of ships shattered upon it in some hurricane of yesterday. There they lie, some more or less scattered, some heaped upon and jammed against each other with sharp angles and outlines wholly unworn and, moreover, so distributed that you see at a glance their strict relation to the existing heights and hollows of the land, which must then have been the shoals and channels of the sea. These contours cannot have been materially changed since that sea was there. It seems that it must have been, geologically speaking, only a few days ago. And this conclusion would seem to be confirmed when we observe the phenomena which are presented in certain cases, where the land has clearly rested for a considerable time, and the ocean has left in raised beaches the evidence of its work at certain levels. Such raised beaches are to be found at many points all round our western coasts. But incomparably the finest and most instructive example of them is to be seen on the west coast of the Island of Jura, near the mouth of Loch Tarhert, Jura, and extending for several miles to the north. These beaches are visible from a great distance, because these rolled pebules are composed entirely of hard white quart zite of the Jura mountains, which resists disintegration, and is unfavourable to the successful establishment of vegetation.

I visited these beaches a few weeks ago, and, measuring the elevation roughly with a graduated aneroid, I found that they represent three more or less distinct stages of subsidence. One beach being about the level of 50 feet above the present sea-level ; another about 75 feet, and a third at about 125 feet. Some others which I saw only from a distance appeared to be higher, and I believe, but am not quite sure, that farther to the north they have been traced to the level of 160 feet. But the feature connected with these sea beaches, and especially with the lowest, or the 50 feet beach, is the evidence it affords--first, of the length of time during which the ocean stocd at that level, and, secondly and particularly, the evidence it affords of the very recent date a which it must have stood there. As regards the length of time during which the ocean must have stood there, it is sufficient to observe the beautiful smoothness and roundness of the pebbles. They have been more thoroughly rolled and polished than the corresponding pebbles on the existing shores, equalling in this respect the famous pebble beds of the beach at Portland. Then, as regards the very recent date at which the ocean mus have stood there, it is difficult to give in words an adequate idea of the impression which must be left on the mind of every one who looks at them. You see the curves left by the sweep of the surf, the summit level of its force, and the hollow behind that summit, which is due to the exhausted crest, all as perfect as if it had been the work of yesterday.

It is difficult to conceive how ordinary atmospheric agencies, and even the tread of sheep and cattle, should not have broken such an arrangement of loose material, but there are exceptionally favourable circumstances for the preservation of these beds from absence of considerable streams and the protection of surround. ing rocks. There is little or no evidence of glaciation anywhere around, and, although it is certain that the sea which stood at those beaches so recently was a sea subject to glacial conditions, it is equally certain either that it continued to work there after those conditions had passed away, or, what is more probable, that that particular line of coast was protected from the drift of surrounding ice floes. If, now, we compare the evidence of recent action in these sea beaches with the similar evidence connected with the position of erratics at higher levels, which can only have been placed there by floating ice, I cannot help coming to the fonclusion that the submergence and re-elevation of the land to the extent of more than 2,000 feet above the level of the present ocean has been one of the very latest changes in the history of this portion of the globe; and, moreover, that the re-elevation has been comparatively rapid, probably by lifts or hitches of considerable extent, and that there were few, if any, pauses or rests comparable in duration with those which are recorded in the Tura beaches and in the cutting of the existing coasts. In conclusion let me repeat that, whether this conclusion is correct or not--and I an well aware of the many difficulties which surround it-the general fact of submergence and re-elevation is, perhaps, as certain as any conclusion of geological science, and that the consequences of it in accounting for the distribution of gravels and the most recent changes of denudation have never as yet been worked out with anything approaching to consistency or completeness.

Professor GeIIsIE, F.R.S., remarked that those who had watched recent discussion in physiographical geology might have been prepared, as he himself was, for a much greater divergence of opinion between the views expressed by the Duke of Argyll and those entertained by the younger school of geologists. While expressing his gratification at this approach, and at the very clear and eloquent views of the author of the paper, he ventured to point out some points where the arguments seemed faulty. He showed that the Highlands might have been covered with Old Red Sandstone, and that the antiquity of the present mountains could not be traced back to the primeval up. heaval to which undoubtedly the general mass of Highland land was due. He pointed out that the absence of raised beaches could not be regarded as a disproof of the former presence of the sea, but indicated a period of pause during either a rapid or protracted upheaval.

Professor HARKNess fully agreed in what Professor Geikie 
had said in reference to the great value of the communication of his Grace. There were, however, some points to which he must take exception. He considered that the arrangement of the strata which form the metamorphic rock of the Highlands was not so difficult to unravel as some inferred. The southern portion of the series in manny spots afforded clear section of the sequence and contortions, and he would specially refer to the section between Loch Tay and Glen Lyon. This section afforded clear evidence of mountains lying in a synciinal trough, a circould not be accounted for by contortions prod.uciog hills and valleys. He also agreed with Professor Geikie in considering that the Old Red Sandstone formerly covered a very large portion of the metamorphic rock, and he was more disposed to refer the outline of the Highlands to superficial denudations than elevations or subsidences of metamorphic strata. He referred to the importance of an investigation of the glaciation of the Outer Hebrides in any effort to snlve the glaciation of the Fighlands and Islands. He had for several years taken observations in these islands in regard to this subject, and the conclusions he had come to were that the whole of these outer islands had been glaciated from the Atlantic to the West; secondly, that during the period of submergence in the glacial epoch, icebergs and floes had dropped blocks on all our islands, many of which were finally perched; thirdly, he thought that local glaciers had also existed in Harris, at least, if not in South Uist. The olaciation of the Outer Islands was remarkably fine and should be visited by all interested in the glaciation of Scotland. Mr. Thomson had examined the conglomerates from the Mull of Kintyre to Loch Inver, in Ross-shire, and had never foind a single section of the strata that contained similar pebbles and boulders to those found on the shores of Jura and Islay. Fe could not agree with Mr. Jolly in saying that the drifted boulders found in the Island of Lewis had all drifted from the West. Many were traceable to the mainland Cambrian age, and were found in Gare Loch and reighbourhood. In reference io the fexures of the valleys he quite agreed with his Grace, and referred to Tarbert, Loch Fyne, where there was one great flexure, rocks being contorted and broken up into every conceivable the belief that the contour of the country was established previous to the deposition of the Mesozoic rocks.

The Rev. H. W. CRosskey remarked that the general glacial phenomena of Scotland could be explained without recurrence to the ice sheet. These phenomena were largely connected with local conditions. The absence of any positive marks of seabeaches was no proof against submergence. In many cases a small deposit accidentally discovered proved the submergence of miles of country. Some great salient facts in the order of events stood fairly established. In the first instance the land stood at a higher level. This was proved by remains of rivers beneath boulder clay, and other facts. Subsidence then occurred, and glacial shell clays were deposited. Owing to subsequent re elevation a slight subsidence probably again took place previous elevation a slight subsid. As regards the last upheaval, he held that it took place gradually. Examination of the clays showed a quick passage from marine to estuarine conditions. He agreed with his Grace that the last upheaval was probably at a recent period, but it must be remembered that the highest beds of fosils of the series consisted of olacial forms. He asked attention to the great general order of the succession of beds.

Prof. W.C. WILIIAMSON, as a siudent of the Midland drifts, was surprised at the apparent agreement among the Scotch yeologists in their non-recognition of Agassiz's ice-sheet. He was not able to acquiesce in their views on two grounds. The question turned upon the meaning of the terms glacietion and icesheet, which were terms representing relative magnitudes. The ice-covering of Greenland was practically an ice-sheet, and yet that it must have a coastward motion was shown by the icebergs which continually and through long ages broke away from it without reducing its area. In like manner the Antarctic ice wiong which the Erebus and Terror sailed for hundreds of miles without break, more than mast high above the water, and seven or eight times that amount below it, must have a similar motion. A gain the condition of the lower till, a true moraine profonde, devoid of all traces of marine life, could not be explained except on the strpposition of a sub-glacial origin, a position in which all life was excluded, a condition intelligible on the supposition of formation under a broad ice-sheet.

Mr. Gwyn Jeffreys and Mr. Pengelly also took part in the discussion. The Duke of Argyll brielly replied, and thanks were accorded to his Grace for his interesting paper.
SECTION D.

BIOLOGY.

Department of Zoology and Botany.

AdDress bX Aefred Newton, F.R.S., F.L.S., V.P.Z.S., Professor of Zoology and Comparative Anatomy in THE UNIVERSTTY OF CAMBRIDGE, VICE-PRESIDENT.

ANy one in the fosition of chairman of this Department must feel that his difficulty lies in choosing rather than in seeking a subject whereon to address an audience like that which is before me. This difficulty arises from the astounding abundance of interesting topics which are presented by the studies of botany and zoology-or of the latter alone, I. may say, since it would ill become me to attempt the treatment of any which belong to the sister science. But it is of course incumbent upon me to touch upon the chief events of the past year which affect this Department ; and it seems possible that in so doing we may find some considerations naturally proceeding from them to be worthy of your notice during the short time that I shall presume to occupy your attention, and also to present enough general interest to justify my enlarging upon the themes which they inspire.

These chief events appear to me to be two in number. It is my first and pleasing duty to congratulate the naturalists here assembled on the successful termination of that expedition in which we have all taken so great an interest, as, during its pro. gress, tidings of it have reached us from one distant land after another, and especially (as your mouth-piece) heartily to welcome home all now present who were on board the good ship Chatlenger in her circumnavigation of the globe. I would that your spokesman on this occasion had been one who was better able to appreciate their labours and enter into details as to the value of their discoveries and researches. Unfortunately $I$ am under the great disadvantage of being so imperfectly acquainted with the mysteries of the ocean, that it is only possible for me to speak in the most general terms of what bas been done. I feel sure, however, that, so far as the great secrets of the sea can yet be interpreted and revealed by men, they will be by those who have happily returned to us, Sir Charles Wyville Thomson and his colleagues. There is one of their company we know they have not brought back; and it is nitting for us to lower the tone of our exultation while we remember the rame of von WillemöesSulm. With this single sad exception there is, however, nothing, so far as I know, to occasion regret; and the various memoirs that have been already published by members of the expedition. give a foretaste of what we may expect when the whole of its results are made known. I am informed that the rich collections made during the voyage are at present lodged in the University of Edinburgh, and are in process of revision and rough arrangement under the superintendence of the Director of the Scientific Staff of the late expedition. They include the products of dredging or trawling and surface-collecting at about 350 stations, and at depths varying from 100 to 4,500 fathoms, and consist of a prodigious number of specimens belonging to most of the groups of marine Invertebrata, especially of Sponges and Echinoderms, which preponderate at the greatest depths. It is, I believe, intended to obtain the assistance of special experts in working out the different groups; and $I$ am sure this meeting will hear with pleasure that the Hydrozoa are to be intrusted to Prof. Allman, and the Polyzoc to Mr. Busk. It is understood that Her Majesty's Treasury will charge itself with the cost of publishing the treatises of these and the other eminent naturalists to be employed ; and thus it is hoped that a series of volumes will be produced worthy of the magnitude of the subject, and fit for the first rank among the works of zoologists in this or any other country. I ned scarcely add that the wishes of all here will be for the due carrying out of this grand scheme; and, re. membering how often similar ambitious undertakings by our scientific men in combination with our Government have been baulked by untoward circumstances, we cannot but express the sincere hope that former failures will serve as useful warnings to ensure future success. I regret extremely my inability to say more on this subject.

I trust you will not think me to underrate the importance of the safe and prosperous return of the Challenger from her voyage, when, though naming it first, I ascribe to it the second place in the events of the past year as regards the progress of zoological investigation. Other scientific expeditions have before now left these shores and the shores of other countries, and have more or less fully attained their purpose while other expeditions will doubtless in due time be organised and carried out with, we 
trust, like happy results. The voyage of the Challenger, though a highly important, and, in many respects, a novel one, is notwithstanding only a unit in a long series which began a century ago, and has been continued at intervals to our own day ; nay, more, since the sailing of the Challenger we have witnessed the departure of another and larger expedition for the accomplishment of a still more arduous undertaking. But what $I$ have now to speak of is a matter that will, if I am not mistaken, in after ages characterise the present year as an epoch in the history of our sciences inferior only in importance to that which marked some eighteen or nineteen years ago the promulgation of a reasonable Theory of Evolution by Mr. Darwin and Mr. Wallace. And while it is to the latter of these two naturalists that we owe the boon that has recently been conferred on us, it is unquestionably from the former labours of both-united yet distinct-that the boon acquires its greatest value. Without those far higher, far wider views which the Theory of Evolution enables us to take, the serried array of facts that bristle throutghout the two volumes of the "Geographical Distribution of Animals" 1 which Mr. Wallace has just published, would have been but a comparatively meaningless aggregation of statements - the evidence no doubt of labour almost unsurpassed, the accumulation of much that is curious and of much that is suggestive, but, taken all in all, as serving to an unintelligible or insignificant end, if to any end whatever that was not misleading.

As the case is, the result is very different. But $I$ would ask you now, Without the aid afforded by the "Doctrine of Descent," would it have been possible to draw, as Mr. Wallace has so skilfully drawn, those legitimate conclusions from a consideration of the animal life of Java (vol. i. pp. 352,353 ), or to arrive at those marvellous results with respect to the past history of Borneo (vol. i. pp. 358,359 ), or even to indulge in those daring speculations with regard to the origin of the Celebesian fauna (vol. i. pp. 436-438)? I cite these instances because they are taken from that part of the world on which the author's labours have before shed so much light, and with which his name is imperish. ably associated; but there is hardly any one of his summaries that does not place before us material for reflection as astounding.

While, however, assigning to the theory of evolution the chief glory in giving a real and lasting value to the interpretation of the facts of animal distribution, I must not omit acknowledging the share which physical geography has contributed to that end, especially by its marine surveys, which furnish the zoologist with data as to the depths of seas and oceans, and thereby enable him to judge as to the former extent of land. It is therefore to be expected that voyages like that of the Challenger, when their results have been fully worked out, will still further add to our knowledge in this respect. Again, too, geology (but this follows almost as a matter of course) has in its own line played an equal part. I would that botany coula be mentioned in this connection, but here it seems as if the eldest of the biological sciences were not, as she usually is, in advance of the rest; and $\mathrm{Mr}$. Wallace's suggestion (vol. ii. p. I62), that zoology furnishes a key wherewith many of the difficulties besetting the study of the distribution of plants may be unlocked, will doubtless meet with due attention from botanists.

Of the care and labour which the author of this work has bestowed upon it, no one here I venture to think, has a better right to speak than myself, because it is not very long ago that I attempted a dissertation on the geographical distribution of a single class of animals. ${ }^{2}$ Though it was the class with which I am most familiar, and though in my attempt $I$ had the invalu. able assistance of Mr. Wallace's manuscript at my side, which cleared my way through many obstacles, still I found the task one of enormous difficulty, and one which I at times almost repented that $\mathrm{I}$ had undertaken; yet $\mathrm{Mr}$. Wallace has treated not of birds only, as I did, but of mammals, amphibians, reptiles, and freshwater fishes-to say nothing of the most telling families of two orders of insects, with the molluscs so far as they were available for his purpose. There is nothing that in turning over the pages of these volumes so much strikes one as the energy they evince on the part of their author. Those who have been most accustomed to the literature of zoology must admit that there is scarcely any book with which "The Geographical Distribution of Animals" may not, in respect of hard and honest

"The Geographical Distribution of Animals, with a Study of tbe Relations of Living and Extinct Faunas as Elucidating the Past Changes of the Earth's Surface." By Alfred Russel Wallace, Author of "The Malay Archipelago," \&c. \&vo, two vols. London, 1876.

a Geographical Distribution of Birds in "Encyclopædia Britannica," Ed. 9, vol. iii, pp. 736-764. wrork, be advantageously compared. It deserves to bear good fruit; and I am greatly mistaken if it will not do so. From an educational point of view, it can hardly fail to be of the greatest service. Attractive as is the subject to those that know it and see its bearings, the learner has hitherto been repelled from its consideration by the want of any work of general compass which would guide his studies, while even few of those treatises which have a particular scope were of much use to him. Mr. Wallace has now placed one in his hands; and the result we need not try to anticipate. One thing, however, is clear-the distribution of animals can no longer be neglected as a secondary or unimportant part of zoology. It only remains for me to add, while thus attempting to set forth the general merits of this learned work, that I by no means pin my faith to all the author's details, or to all his conclusions. Most of the latter may indeed be justified by the present imperfect state of our knowledge; but it does not follow that they will eventually meet with common acceptance. I must particularly call your attention to the admirably cautious words in which he talses leave of his readers - words that prove him to be thoroughly imbued with the right spirit of a true worker in a progressive branch of study. Mr. Wallace says :-

"The preceding remarks are all I now venture to offer on the distinguishing features of the various groups of land-animals as regards their distribution and migrations. They are at best but indications of the various lines of research opened up to us by the study of animals from the geographical point of view, and by looking upon their range in space and time as an important portion of the earth's history. . . . Till every well-marked district-every archipelago, and every important island, has all its known species of the more important groups of animals catalogued on a uniform plan, and with a uniform nomenclature, a thoroughly satisfactory account of the geographical distribution of animals will not be possible."

And then he goes on to point out that more than this is wanted :-

"Many of the most curious relations between animal forms and their habitats, are entirely mnoticed, owing to the productions of the same locality never being associated in our museums and collections. A few such relations have been brought to light by modern scientific travellers; but many more remain to be discovered, and there is probably no fresher or more productive field still unexplored in natural history."

These coincident variations, he concludes by saying, "have never been systematically investigated. They constitute an unworked mine of wealth for the enterprising explorer; and they may not improbably lead to the discovery of some of the hidden laws (supplementary to natural selection) which seem to be required in order to account for many of the external characteristics of animals" (vol. ii. pp. 552, 553)

And now to follow out the idea with which $I$ began. Having touched on the two chief zoological events of the year, let us see if they do not suggest something that will not be beneath your consideration for the remainder of this address. I have spoken of the certainty of the expedition from which we now welcome our friends being succeeded by others of similar character. We shall hardly be indulging any vain imagination if we ask ourselves what we may look forward to as regards their reports; and to one point we may perhaps usefully apply ourselves.

What if a future Challenger shall report of some island, now known to possess a rich and varied animal population, that its present fauna has disappeared? that its only mammals were feral pige, goats, rats, and rabbits-with an infusion of ferrets, introduced by a zealous "acclimatizer" to check the superabundance of the rodents last-named, but contenting themselves with the colonists' chickens? that sparrows and starlings, brought from Europe, were its only land-birds, that the former had propagated to such an extent that the cultivation of cereals had ceased. to pay-the prohibition of bird-keeping boys by the local schoolboard contributing to the same effect-and that the latter (the starlings) having put an end to the indigenous insectivorous birds by consuming their food, had turned their attention to the settlers' orchards, so that a crop of fruit was only to be looked for about once in five years-when the great periodical cyclones had reduced the number of the depredators? that the goats had destroyed one half of the original flora, and the rabbits the rest? that the pigs devastated the potato-gardens, and yam-grounds? This is no fanciful picture. I pretend not to the gift of prophecy; that is a faculty alien to the scientific mind; but if we may reason from the known to the unknown, from what has bcen and from what is to what will be, I cannot entertain a doubt that 
these things are coming to pass; for I am sure there are places where what is very like them has already happened.

You may ask why this is so? why do these lands so speedily succumb to the strangers from beyond sea? One part of the answer is ready to hand with those who have learned one of the first principles of biology which our great master, Mr. Darwin, has laid down for us. The weaker, the more generalised forms of life must always make way for the stronger and more special. ised. The other part of the answer is supplied by Mr. Wallace; for no one can have studied his volumes to much purpose with. out perceiving that the inhabitants of oceanic islands and of the southem hemisphere-the great Australian Region especially, and South America not much less, are the direct and comparatively speaking little-changed descendants of an older, a more generalised and a weaker fauna than are the present inhabitants of this quarter of the globe, which have been, so to speak, ela. borated by nature and turned out as the latest and most perfect samples of her handiwork.

Set face to face with unlooked-for invaders, and forced into a contest with them from which there is no retreat, it is not in the least surprising that the natives should succumb. They have hitherto only had to struggle for existence with creatures of a like organisation; and the issue of the conflict which has been going on for ages is that, adapted to the conditions under which they find themselves, they maintain their footing on grounds of equality among one another, and so for centuries they may have "kept the noiseless tenor of their way." Suddenly man interferes and lets loose upon them an entirely new race of animals, which act and react in a thousand different fashions on their circumstances. It is not necessary that the new comers should be predacious; they may be so far void of offence as to abstain from assaulting the aboriginal population; but they occupy the same haunts and consume the same food. The fruits, the herbage, and other suppiies that sufficed to support the ancient fauna now have to furnish forage for the invaders as well. Their effects on the flora there is no need for me to trace, since Dr. Ilooker expressly made them one of the themes of that discourse to which many of us listened with rapt attention a few years since at this Association. But the consequences of the inyasion to the native fauna have never been so fully made known. The new comers are creatures whose organisation has been prepared by and for combat throughout generations innumerable. Their ancestors have been elevated in the scale of being by the discipline of strife. Their descendants inherit the developed qualities that enabled those ancestors to win a hard-fought existence when the animals around them were no higher in grade than those among which the descendants are now thrown. Can we doubt that the victory inclines to the heirs of the ancient conquerors? The struggle is like one between an army of veterans and a population unused to warfare. It is that of Spaniards with matchlocks and coats of mail against Aztecs with feather cloaks and bows and arrows. Mala salus victis. A few years, and the majority of native species are exterminated. But this is not the worst. The species which perish most quickly are just those that naturalists would most wish to preserve; for they are those peculiar and endemic forms that in structure and constitution represent the ancient state of things upon the earth, and supply us with some of the most instructive evidence as to the order of nature.

With the progress of civilisation it is plain that there will soon be hardly a land but will bear the standard of a European nation or of a community of European descent, and, as things are going on, be overrun by their imports. If this were inevitable, it would be useless to complain. But is it inevitable? Is it not obvious that most of this extermination is being carried on unwittingly, and may not some of it be avoided by proper precautions? If so, should not men of science make a stand, and interest the ignorant or careless in the importance of the subject? I cannot divest myself of the belief that the course of the next century will see the extirpation, not only of most of the peculiar faunas I had in view a few minutes ago, but of a great multitude of other species of animals throughout all parts of the world. The regret with which I regard such extirpation is not merely a matter of sentiment. Here sentiment and science are for once on the same side. A heavy blow will be inflicted on zoology by the disappearance of some of these marvellous and peculiar forms. There is no one species of animal whose structure and habits have been so completely investigated that absence of the means of further examination would not be a distinct deprivation to science; and as what Science has done is only an earnest of what she will do, we cannot say that the time shall ever come when the want of those means will not be severely felt. It is then for scientific men, and for naturalists especially, to consider whether they are not bound, in the interest of their successors, to interpose more than they have hitherto given any sign of doing.

But outside this audience there are many who care little for consequences like these. Such persons may, however, be impressed by thinking that the indiscriminate destruction of animals which, in one way or another, is now going on, must sooner or later lead to the extirpation of many of those which minister to our wants, whether of comfort or luxury. The fur-bearing creatures will speedily, if they do not already, require some protection to be generally accorded to them; and that such protection can be effectually given is evident if we take the trouble of inquiring as to the steps taken by the Russian local authorities in Alaska, and now, I believe, continued by those of the United States, for limiting the slaughter of the sea-otter and the furseals of the adjacent islands to particular seasons. No one can suppose that, even with the assistance we get from Siberia, our supply of ivory will continue what it now is when the interior of Africa is pacified and settled, as we can hardly doubt that it one day will be; and, unless we can find some substitute for that useful substance before that day comes, it would be only prudent to do something to check the wasteful destruction of elephants. Many people may think that the continent of A frica is too vast, and its animal life too luxuriant, for the efforts of man materially to affect it. If we inquire, however, we shall find that this is not the case, and that there is an enormous tract of country, extending far beyond our colonies and the territories of the neighbouring republics, from which most of the larger mammals have already disappeared. There is good reason to believe that at least one species has become extinct within the last five-and-twenty years or thereabouts; and though I do not mean to say that this speeies, the true zebra, had any economic value, yet its fate is an indication of what will befall its fellows; while to the zoologist its extirpation is a matter of moment, being probably the first case of the total extinction of a large terrestrial mammal since the remote days when the Megaceros hibernicus cisappeared.

Time would fail me if I attempted to go into particulars with regard to the marine Mammalia. It is notorious that various members of the orders Sirenia, Cetacea, and Pinnipedia, have recently dwindled in numbers or altogether vanisied from the earth. The manatee and dugong have been recklessly killed off from hundreds of localities where but a century or so since they abounded; and with them the stores of valuable oil that they furnished have been lost. That very remarkable Sirenian, the huge Rhytina gigas has become utterly extinct. The greed of whalers is believed to have had the same effect on a Cetacean (the Balana biscayensis) which was once the cause of a flourishing industry on the coasts of France and Spain. The same greed has almost exterminated the right-whale of the northern seas, and is fast accomplishing the same end in the case of seals all over the world. You are probably aware that an Act of Parliament, passed in the session of 1875 , was intended to put some check upon those bloody massacres that annually take place on the floating ice of the North Atlantic, to wlich these creatures resort at the time of bringing forth their young, when

$$
\text { "Sires, mothers, cbildren in one carnage lie." }
$$

But, whether through official indifference, or what, I know not, the treaties with foreign nations authorised by that Act were not completed; and last spring, at the solicitation of certair Aberdeen or Peternead shipowners, the Board of Trade allowed "one year more" of wholesale slaughter. Whatever other nations might like to do, our hands at least should have been unstained. It is admitted that in certain manufactures - that of jute, for instance-animal oil is absolutely necessary. It is easy to see that before long there will be very little animal oil forthcoming.

There is another class of animals with whose well-being the interests of man are largely connected. It cannot be denied that our fisheries are year by year subjected to an ever-increasing strain, through the rapidly increasing population of these islands, and are giving unmistakable signs of being unable to bear it. But it must be admitted that the consideration of their case is fraught with unusual difficulties. Commissions, either Royal or Parliamentary, have been appointed one after another to inquire into the facts and to seek a remedy, if one is to be found, for the falling off. It is with great diffidence that I venture to pass any criticism on the recommendations made by those Commis. 
sions, and especially on such as were contained in the Report of a Commission the constitution of which was such as to inspire the greatest respect, since men so eminent as Prof. Huxley and Mr. Holdsworth were named in it. That Commission reported in effect that there was nothing to be done with our sea-fisheries but to leave things alone. I do not profess to quote the words of the Report (which, indeed, I have not seen for a long time); but in substarce, I believe, it amounted to this:-That the natural enemies to which fishes were exposed were so multitudinous, so crafty, and so rapacious, that their destruction by man was very slight in comparison, and that his interference might be safely neglected in considering its consequences. Now it has always seemed to me that the Commissioners on this occasion suffercd themselves to be deceived. Well aware of how little is known as to the indirect effects of man's acts in regard to the lower animals, and in their fear lest any unforeseen bad results should follow from measures intended to be remedial, they recommended none at all. But I fail to discern that land or sea makes any essential difference in the laws of life. The balance of nature must be preserved as steadily in a dense as in a rare Huid -in water as in air--or all will not go well. Whatever be the weight in either scale, equipoise is as easily destroyed by an ounce as by a ton. The marine fishes that are of such commercial importance (cod, herrings, and the like) have naturally, no doubt, enemies innumerable-dogfish, cormorants, porpoises, and what not; but we know that, owing to their fertility and habits, the cod and herrings have continued till lately to contend successiully with these drawbacks and to maintain their numbers. It matters not if only one egg of the 10,000 , or whatever be the number in the roe of a herring, produces a fish that arrives at maturity and escapes its natural enemies, so long as that one fish is sufficient to supply the place of its parent. Now this, according to the arrangement of nature, has hitherto been the case. But if, instead of that fish living to propagate its kind, it is cut off before its time by an enemy against whom nature has made no provision, her balance is at once destroyed; and the oftener the operation is repeated the sooner will the numbers of the species dwindle; and the dwindling will go on in a rapidly accelerated ratio. Therefore it seems that, so far from leaving our sea-fisheries unrestricted, it is highly necessary to impose some limitation upon them; and, so far from dreading interference, our interference is at present so fatal that further interference of another kind is required as a counterbalance; while that counterbalance science only can apply.

As much may be said for those other industries, in common speech also called "fisheries"--the taking of oysters, crabs, and Iobsters, all of which have lately been diminishing in a still more alarming degree. Here Parliament has wisely resolved to interpose, though whether the manner of interposition is wise seems to be a matter on which, as few naiuralists have been consulted, we had better reserve our opinion.

Thus, without troubling you with many technical details, I have striven to lay before you a sketch of man's treatment of some of his fellow.creatures, and of the effects which have sprung, or certainly will spring, from it. There is probably hardly an island on which he has set foot the fauna and flora of which has not been in some degree influenced by his even temporary presence; there is assuredly not a continent, though a continent takes longer to subdue: and his control does not stop at the shore; for, if what I have been advancing is true, the inhabitants of the deep come also more or less under his dominion. I invite you to contemplate whether it is aiways, or even generally, that of a beneficent ruler. But it will, doubtless, be urged that this kind of thing has gone on for ages-ever since life first existed on the earth. I may be told, in the words of the gxeat poet of the conntry in which we now find ourselves-

$$
\begin{aligned}
& \text { "Look abroad through Nature's range, } \\
& \text { Nature's mighty law is change; } \\
& \text { * Why then ask of silly man, } \\
& \text { To oppose great Nature's plan?" }
\end{aligned}
$$

I would answer from the same source that

$$
\text { "A-man, to whom alone is giv'n, }
$$

should by means of that ray not oppose nature, but rather second her preservative measures. That ray is the ray of science. We can only govern nature by obeying her, only by obeying her can we assist her. To obey her laws we must know them; what can we know of them but what science teaches us?

It may be said that I have taken too gloomy a view of this matter of the extirpation of animals by man. I wish I could think so. But $\mathrm{I}$ believe that if we go to work in the right way there is yet time to save many an otherwise expiring species. In this country there is happily a strong disposition, which grows stronger day by day, to preserve our wild animals. It is very desirable that this feeling should not be limited to the British Islands. If it is, as I maintain, a right feeling - a feeling sanctioned alike by humanity, by science, and by our own material interests-it cannot be too widely disseminated. But its propagation must not be left to humanitarians and sentimentalists, whose efforts are sure to be brought to nothing through ignorance and excess of zeal, nor to economists, whose endeavours would unquestionably fall short of what is required. The officiousness of the one class and the slackness of the other must equally be tempered by the naturalist. He can be trusted not to interfere with the use, but with the abuse, of the animal world. Only to do this he must place himself in the forefront of the movement; for he can submit to no other leader. He alone has, or should have, that knowledge which gives the power of coping successfully with the difficult questions that will arise ; and the advantage it gives him he must not abstain from exercising. If, without offence, I might here paraphrase some venerable words, I would say that, according to the greatness of this power, we must preserve those that are otherwise appointed to die.

\section{THE NORWEGIAN ATLANTIC EXPEDITION'}

$I N$ continuation of my last notice, I may say that the Expedition stayed at Reikiavik from July 26 to Aug. 3. While Capt. Wille marle magnetical observations on shore, the majority of the members of the expedition made a tour to Thingvalla, where they had the pleasure of falling in with an Englishman coming from the north and bound for the Geysers; we had a very happy evening together. The remarkable geological structure of the country attracted much interest. The excursion party returned July 30. Stormy weather prevailed during the whole stay at Reikiavik, so that the coaling was much delayed, and no magnetical observations could be made on shore. A small leak in the boiler took up most of the last day to set it right, and at last we got away on the evening of the $3 \mathrm{rd}$. The season was now so far gone that we were obliged to give up the idea of exploring the sea between Iceland and Greenland, and we shaped our course south of Iceland again, and then towards N.E., running out a line of soundings which showed the transition from the warmer Atlantic water at the bottom, to the ice-cold Arctic water east of Iceland. During a dredging on the bank, between Iceland and Färöe, on a hard, probably volcanic, bottom, the line got fast on a ruck, and it became necessary to break it ; we thus lost a dredge and some hundred fathoms of dredging line. From a point east of Iceland, the course was laid for Namsos, and several deep sea stations were well explored on this line. The depth at first increased from I, 000 fathoms to I, 500 , and at last to 1,800 , the last being midway between Norway and Iceland in lat. $64^{\circ} 65^{\prime}$. The more easterly soundings gave a less depth, the last of them being only 650 fathoms. The temperature at the bottom was always under $32^{\circ}$; at $\mathbf{I}, 800$ fathoms it was $29^{\circ}$, corrected for the error of the thermometer, and for that caused by pressure. The layer with $32^{\circ}$ was found in about 200 fathoms east of Iceland, and in 300 or 400 fathoms further east. It seems that the Färöe bank preverts the warm Atlantic water from filling up the upper layers of the northern seas to such a depth on the north-east side of these islands, as it does in the interval between this region and the cold sea east of Iceland. The nearer Norway the warmer is thas upper layer of the sea, not only on the surface, but at the depths of 100 and 200 fathoms.

The fauna of the Arctic deep sea seems to be very constant, while it is not very rich; the same specimens have been found farther south in ice-cold water, but none of the large forms found in ice-cold water near the coasts (were met with by us ${ }^{2}$ ). The bottom consists of mud, with innumerable specks of small round calcareous shells.

During the last cruise, the weather was constantly bad; nevertheless, it has been possible to work the deep-sea apparatus even in gales, and with a sea in which the ship went bowsprit under. This result has been attained after successive experiments. The last working day the dredge and trawl were sent out together, the latter behind the former. The weather was stormy, the sea very high, but the experiment was made, and the dredge came well on board. After this result, we can now see no objection to working all the deep-sea apparatus in any kind of summer

I Contunued from $\mathrm{p} \cdot 33^{8}$.

2 Probable omission in origiral. 